\title{
Binding Free Energy (BFE) Calculations and Quantitative Structure-Activity Relationship (QSAR) Analysis of Schistosoma mansoni Histone Deacetylase 8 (smHDAC8) Inhibitors
}

\author{
Conrad V. Simoben ${ }^{1}$, Ehab Ghazy ${ }^{1}$, Patrik Zeyen ${ }^{1}$, Salma Darwish ${ }^{1}$, Matthias Schmidt ${ }^{1}$, \\ Christophe Romier ${ }^{2}$, Dina Robaa ${ }^{1}$ and Wolfgang Sippl ${ }^{1, *(1)}$
}

1 Institute of Pharmacy, Martin-Luther University of Halle-Wittenberg, 06120 Halle (Saale), Germany; veranso.conrad@gmail.com (C.V.S.); ehab.ghazy@pharmazie.uni-halle.de (E.G.); patrik.zeyen@pharmazie.uni-halle.de (P.Z.); salma.darwish@pharmazie.uni-halle.de (S.D.); matthias.schmidt@pharmazie.uni-halle.de (M.S.); dina.robaa@pharmazie.uni-halle.de (D.R.)

2 Département de Biologie Structurale Intégrative, Institut de Génétique et Biologie Moléculaire et Cellulaire (IGBMC), University of Strasbourg, CNRS, INSERM, 1 rue Laurent Fries, CEDEX, 67404 Illkirch, France; romier@igbmc.fr

* Correspondence: wolfgang.sippl@pharmazie.uni-halle.de; Tel.: +49-345-5525040

Citation: Simoben, C.V.; Ghazy, E.; Zeyen, P.; Darwish, S.; Schmidt, M.; Romier, C.; Robaa, D.; Sippl, W. Binding Free Energy (BFE) Calculations and Quantitative Structure-Activity Relationship (QSAR) Analysis of Schistosoma mansoni Histone Deacetylase 8 (smHDAC8) Inhibitors. Molecules 2021, 26, 2584. https://doi.org/ $10.3390 /$ molecules 26092584

Academic Editor: Julio Caballero

Received: 31 March 2021

Accepted: 25 April 2021

Published: 28 April 2021

Publisher's Note: MDPI stays neutral with regard to jurisdictional claims in published maps and institutional affiliations.

Copyright: (c) 2021 by the authors. Licensee MDPI, Basel, Switzerland. This article is an open access article distributed under the terms and conditions of the Creative Commons Attribution (CC BY) license (https:// creativecommons.org/licenses/by/ $4.0 /)$.

\begin{abstract}
Histone-modifying proteins have been identified as promising targets to treat several diseases including cancer and parasitic ailments. In silico methods have been incorporated within a variety of drug discovery programs to facilitate the identification and development of novel lead compounds. In this study, we explore the binding modes of a series of benzhydroxamates derivatives developed as histone deacetylase inhibitors of Schistosoma mansoni histone deacetylase ( $s m$ HDAC) using molecular docking and binding free energy (BFE) calculations. The developed docking protocol was able to correctly reproduce the experimentally established binding modes of resolved $s m \mathrm{HDAC} 8$-inhibitor complexes. However, as has been reported in former studies, the obtained docking scores weakly correlate with the experimentally determined activity of the studied inhibitors. Thus, the obtained docking poses were refined and rescored using the Amber software. From the computed protein-inhibitor BFE, different quantitative structure-activity relationship (QSAR) models could be developed and validated using several cross-validation techniques. Some of the generated QSAR models with good correlation could explain up to $73 \%$ variance in activity within the studied training set molecules. The best performing models were subsequently tested on an external test set of newly designed and synthesized analogs. In vitro testing showed a good correlation between the predicted and experimentally observed IC $_{50}$ values. Thus, the generated models can be considered as interesting tools for the identification of novel smHDAC8 inhibitors.
\end{abstract}

Keywords: binding free energy calculations; Schistosoma mansoni; histone deacetylase inhibitors; quantitative structure-activity relationship (QSAR)

\section{Introduction}

Neglected parasitic diseases have been responsible for morbidity and mortality of hundreds of millions of humans in underprivileged communities especially in parts of the Middle East, South America, Southeast Asia and, particularly, in sub-Saharan Africa for over many decades [1]. Amongst these neglected parasitic diseases is schistosomiasis (bilharzia), which is a common intravascular parasitic infection in humans caused by Schistosoma spp. [2]. Despite being a preventable illness, chronic infection is associated with long-term undernutrition, anaemia, organ scarring and fibrosis, resulting in disabling patient symptoms [2-4]. According to the World Health Organization (WHO), an estimated 206.5 million people required preventive treatment for schistosomiasis, out of which 
more than 89 million people were reported to have been treated [3,4]. Several detailed studies/reviews explaining the epidemiology of schistosomiasis have been published [1-5]. In recent years, national and international programs have been implemented in regular drug administration to control or prevent Schistosoma infections. Interestingly, there has been a decrease in the number of infected individuals. However, with no available vaccine, new small molecule inhibitors to treat the disease are needed. In addition, drug resistance problems have been reported for the current drug of choice, praziquantel [2,6-10].

A promising strategy to treat schistosomiasis amongst other parasitic diseases is to target the epigenome of the parasite [11-13]. Histone modifying proteins have thus emerged as potential targets to modulate the epigenome of this parasite in the hope to treat this parasitic ailment. Among these histone modifying proteins are histone deacetylases (HDACs, sometimes also referred to as lysine deacetylases, KDACs), which function by regulating the deacetylation of histone lysine residues as a part of DNA transcriptional regulation [14]. An upset of this balance can lead to hypoacetylation or hyperacetylation leading to the manifestation of diseases such as cancer, inflammation, etc. Conventionally, there are 18 known human HDAC isoforms divided into four major classes (classes I, II, III and IV) depending on their homology to yeast (Saccharomyces cerevisiae) HDACs [15]. While class I (HDAC1, 2, 3 and 8), class IIa (HDAC4, 5 and 7), class IIb (HDAC6 and 10) and class IV (HDAC11) are $\mathrm{Zn}^{2+}$-dependent for their deacetylase activity, class III (Sirtuins 1-7) are nicotinamide adenine dinucleotide $\left(\mathrm{NAD}^{+}\right)$-dependent protein deacetylases [15-20]. Although HDACs have recently emerged as potential targets to treat cancer and parasitic diseases amongst others, the biology behind the effect of HDAC inhibition on these diseases is still not fully understood [21-25].

For over three decades, HDACs have been targeted for various cancer treatments which have resulted in the approval of five HDAC inhibitors with several others in clinical trials for the treatment of several types of cancer [26-38]. Most of the designed, developed and reported HDAC inhibitors have a general structural pharmacophore consisting of three features-the zinc-binding group (ZBG), the linker and the capping group (cap) [39-42]. Additionally, HDAC inhibitors bearing a hydroxamate group chelating the catalytic zinc ion are the most investigated. Due to the partially conserved nature across the active site in all HDACs with a substrate binding channel and the relatively similar pharmacophoric features of the reported HDAC inhibitors, the desired isoform(s) selectivity represents a challenge $[27,43,44]$. Many of the published hydroxamate-type inhibitors inhibit most HDAC isoforms, which limits their use as pharmacological tools and may lead to side effects in the clinic. Resolved crystal structures also reveal that a majority of the hydroxamate derivatives, as well as some other reported zinc chelating groups are able to coordinate the catalytic zinc ion in a bidentate fashion $[45,46]$. Nevertheless, some recently released crystal structures of HDAC6 isoform shows that some HDAC inhibitors coordinate the catalytic zinc ion in a mono-dentate fashion $[47,48]$. In addition to the zinc ion coordination, HDAC inhibitors are further stabilized by hydrogen bonds, mostly with the two conserved histidine residues and the catalytic tyrosine residue, as well as van der Waals and $\pi-\pi$ interaction(s) amongst others.

Several studies have explored the major pharmacophoric features and interactions observed with HDAC inhibitors for the development of new drug candidates against schistosomiasis to target the parasite's epigenome [49]. To reduce the potential side effects of the new molecules, specific targeting of schistosomal HDACs is very important [50]. Interestingly, the human orthologue of $S$. mansoni HDAC8 (smHDAC8), human HDAC8 (hsHDAC8), is less abundant in humans than other class I HDACs (HDAC1 and 3) except in some tumor cells where it is up-regulated [51]. Thus, the development of small-molecule smHDAC 8 inhibitors represents a promising approach for the treatment of schistosomiasis. We have previously reported on a series of $s m$ HDAC 8 inhibitors through virtual screening-based identification and structure-guided optimization [49,52-54]. Application of computational methods to aid our quest for new smHDAC8 inhibitors led to the identification of several potential scaffolds $[52,54]$. Amongst the identified scaffolds, the 
$m$-substituted benzhydroxamates were identified as promising lead structures and further structural optimization studies of this series led to potent smHDAC8 inhibitors [54]. The developed benzhydroxamates exerted interesting selectivity over relevant human HDAC isoforms (HDAC1, 3 and 6; in some cases also HDAC8) and induced apoptosis and mortality of schistosomes in cellular assays. Selectivity of these molecules has been attributed to the possibility of these molecules to target the side pocket present in HDACs 6 and 8 as stipulated in the binding modes from docking procedures and resolved crystal structures. Furthermore, some selected compounds displayed significant dose-dependent killing of the schistosome larvae and markedly impaired egg laying of adult worm pairs maintained in culture.

In this study, we first set to generate structure-based QSAR models that were able to explain variations in the determined $s m \mathrm{HDAC} 8 \mathrm{IC}_{50}$ values. The validated models were subsequently used to predict the activities of some newly designed benzhydroxamate derivatives as $5 m$ HDAC 8 inhibitors and to propose the most promising ones for synthesis and biological evaluation.

\section{Results and Discussion}

\subsection{Diversity Analysis of Dataset(s)}

In order to develop a robust QSAR model, accuracy and precision of the biological data are very important. Thus, the selection of molecules to build the model holds a critical place in the development process. A critical aspect of the selection is to focus on a particular series/chemical space of molecules while covering a reasonable biological activity range. In this study, benzhydroxamic acids-an important class of HDAC inhibitors that we recently developed as inhibitors of the HDAC8 isoform (see the Materials and Methods section) constituted the training set molecules. These molecules in the training set can be generally characterized by the scaffolds depicted in Figure 1, were R1 (at the para position) represents small groups like hydrogen, halogen, methyl, methoxy, while R2 (meta position) represents aromatic substitutions. Reported studies show that this class of molecule has well-established interactions with amino acids residues within the binding site of $s m \mathrm{HDAC} 8$. For instance, the hydroxamate function (ZBG) coordinates the catalytic $\mathrm{Zn}^{2+}$ ions while additionally forming hydrogen-bond interactions with Tyr304, His140 and/or His141. On the other hand, the carbonyl functional group (in the case of the amides-scaffold) forms a hydrogen bond with Lys20 while the amide/amine $\mathrm{H}$ atom is observed to form hydrogen bond with His292. We began our studies by analyzing the diversity of the selected compounds (Figure 1 and Table 1 for information about the selected compounds) using principal component analysis (PCA). The applicability domain of the studied dataset can be used to define a model's limitations. Figure 2 shows the twodimensional (2D) plot of the variations (Figure 2A) and the 3D representation (Figure 2B) of the three most important components (PCA1, PCA2 and PCA3) of the computed descriptors (a_heavy, b_1rotN, b_single, lip_acc, lip_don, mr, PEOE_VSA_POL, TPSA, h_logD and PEOE_VSA_FPPOS) for the training dataset. Distribution of the three most important PCAs after linear transformation using PCA showed that the molecules used in this study were distributed homogeneously within the PCA space. Interestingly, analysis of the three most important principal components of the molecular descriptors space could explain approximately $100 \%$ covariation of the global information of the original space. 

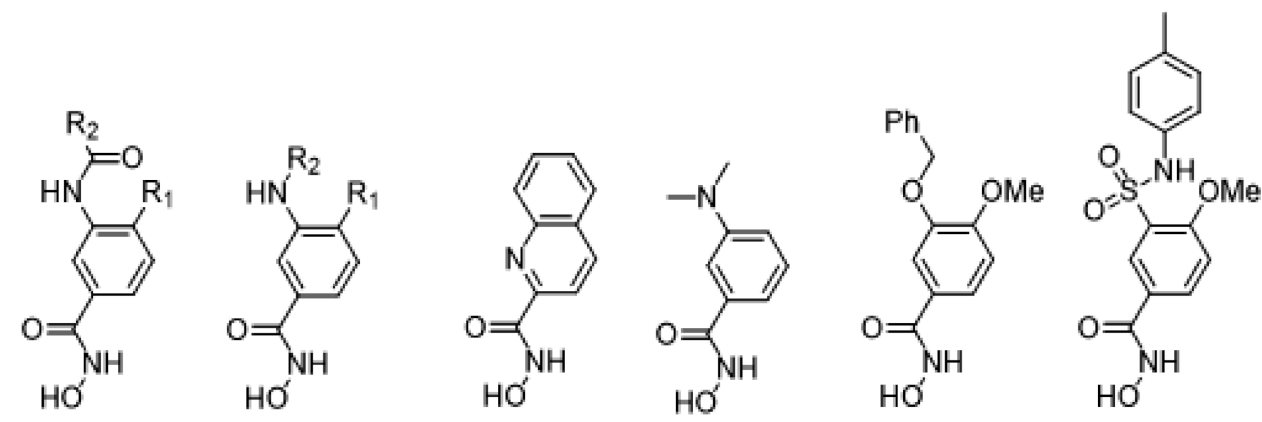

$\begin{array}{llll}\text { Scaffold A } & \text { Scaffold B } & \text { TH58 } & \text { TH36 }\end{array}$

TH70

TH71

Figure 1. Training set molecules.

Table 1. Training set molecules and their respective experimental $\mathrm{pIC}_{50}$ and $\mathrm{SP}$-Docking Sores.

\begin{tabular}{|c|c|c|c|c|c|c|c|}
\hline Name & $\begin{array}{l}\text { Compound } \\
\text { Code }\end{array}$ & Scaffold & $\mathbf{R}_{1}$ & $\mathbf{R}_{2}$ & $\begin{array}{l}\text { smHDAC8 } \\
\mathrm{IC}_{50}(\mathrm{nM})\end{array}$ & $\begin{array}{c}\text { pIC }_{50^{-}} \\
\text {smHDAC8 }\end{array}$ & $\begin{array}{l}\text { GLIDE } \\
\text { SP_Score }\end{array}$ \\
\hline TH100 & $13 r$ & A & methoxy & 4-ethoxyphenyl & $305 \pm 35$ & 6.52 & -7.14 \\
\hline TH101 & $13 \mathrm{~s}$ & $\mathrm{~A}$ & methoxy & benzyl & $183 \pm 39$ & 6.74 & -7.51 \\
\hline TH104 & $13 z$ & $\mathrm{~A}$ & chloro & 2,4-dichlorophenyl & $191 \pm 17$ & 6.72 & -7.20 \\
\hline TH31 & $13 a$ & $\mathrm{~A}$ & hydrogen & phenyl & $468 \pm 79$ & 6.33 & -8.52 \\
\hline TH33 & $13 b$ & $\mathrm{~A}$ & methyl & phenyl & $154 \pm 0.03$ & 6.81 & -7.48 \\
\hline TH39 & $13 c$ & A & methoxy & phenyl & $135 \pm 0.03$ & 6.87 & -7.60 \\
\hline TH60 & $13 k$ & A & methyl & 2-quinolyl & $96 \pm 13$ & 7.02 & -7.04 \\
\hline TH61 & $13 \mathrm{e}$ & A & chloro & phenyl & $67 \pm 10$ & 7.17 & -7.31 \\
\hline TH65 & 131 & $\mathrm{~A}$ & methoxy & 4-biphenyl & $293 \pm 35$ & 6.53 & -7.35 \\
\hline TH66 & $13 \mathrm{~h}$ & $\mathrm{~A}$ & ethoxy & phenyl & $129 \pm 8$ & 6.89 & -7.43 \\
\hline TH67 & $13 \mathrm{i}$ & A & propoxy & phenyl & $267 \pm 49$ & 6.57 & -7.51 \\
\hline TH68 & $13 n$ & $\mathrm{~A}$ & methoxy & 4-chlorophenyl & $146 \pm 4$ & 6.84 & -7.34 \\
\hline TH69 & $13 \mathrm{~m}$ & $\mathrm{~A}$ & methoxy & 4-methoxyphenyl & $106 \pm 18$ & 6.97 & -7.31 \\
\hline TH74 & $13 t$ & $\mathrm{~A}$ & chloro & 4-methoxyphenyl & $147 \pm 5$ & 6.83 & -7.65 \\
\hline TH75 & $13 f$ & A & bromo & phenyl & $150 \pm 9$ & 6.82 & -7.41 \\
\hline TH76 & $13 \mathrm{~d}$ & A & fluoro & phenyl & $178 \pm 8$ & 6.75 & -7.28 \\
\hline TH83 & $13 j$ & $\mathrm{~A}$ & isopropoxy & phenyl & $220 \pm 56$ & 6.66 & -8.58 \\
\hline TH85 & 130 & $\mathrm{~A}$ & methoxy & 2-chlorophenyl & $351 \pm 16$ & 6.45 & -7.22 \\
\hline TH86 & $13 p$ & $\mathrm{~A}$ & methoxy & 2,4-dichlorophenyl & $122 \pm 19$ & 6.92 & -7.98 \\
\hline TH92 & $13 z a$ & $\mathrm{~A}$ & ethoxy & 4-biphenyl & $92 \pm 26$ & 7.04 & -8.58 \\
\hline TH93 & $13 x$ & $\mathrm{~A}$ & chloro & 4-chlorophenyl & $235 \pm 10$ & 6.63 & -7.36 \\
\hline TH94 & $13 g$ & A & trifluoromethyl & phenyl & $140 \pm 8$ & 6.86 & -7.10 \\
\hline TH95 & $13 q$ & $\mathrm{~A}$ & methoxy & 3-biphenyl & $290 \pm 20$ & 6.54 & -7.28 \\
\hline TH96 & $13 y$ & $\mathrm{~A}$ & chloro & 4-nitropheny & $394 \pm 50$ & 6.40 & -7.06 \\
\hline TH77 & $13 u$ & $\mathrm{~A}$ & chloro & 3-benzyloxyphenyl & $378 \pm 45$ & 6.42 & -9.49 \\
\hline TH78 & $13 \mathrm{v}$ & $\mathrm{A}$ & chloro & 3-phenoxyphenyl & $396 \pm 43$ & 6.40 & -9.55 \\
\hline TH81 & $13 w$ & $\mathrm{~A}$ & chloro & 4-phenoxyphenyl & $620 \pm 70$ & 6.21 & -8.85 \\
\hline TH58 & $14 a$ & - & - & 1 $\quad-$ & $8210 \pm 1300$ & 5.09 & -7.51 \\
\hline TH36 & $10 \mathrm{c}$ & - & - & - & $1722 \pm 910$ & 5.76 & -7.41 \\
\hline TH70 & $15 a$ & - & - & - & $268 \pm 21$ & 6.57 & -7.34 \\
\hline TH71 & $16 a$ & - & - & - & $485 \pm 158$ & 6.31 & -7.58 \\
\hline TH28 & $10 \mathrm{a}$ & $\mathrm{B}$ & hydrogen & benzyl & $1040 \pm 250$ & 5.98 & -7.15 \\
\hline TH32 & $10 \mathrm{~b}$ & B & hydrogen & cyclohexyl & $3630 \pm 620$ & 5.44 & -6.80 \\
\hline TH35 & $10 \mathrm{e}$ & $\mathrm{B}$ & methyl & cyclohexyl & $600 \pm 196$ & 6.22 & -7.16 \\
\hline
\end{tabular}

${ }^{*}$ Compound code from the original publication (Heimburg et al. [54]). 


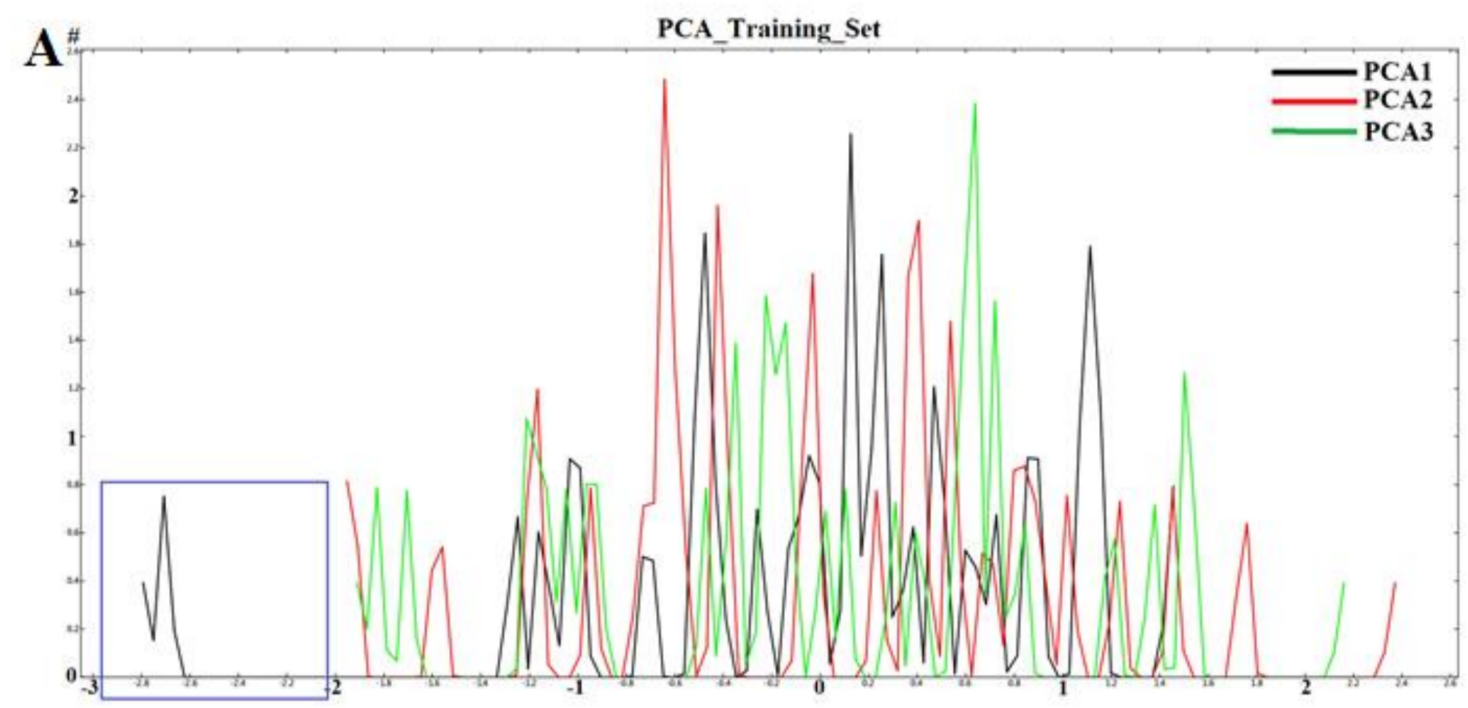

B

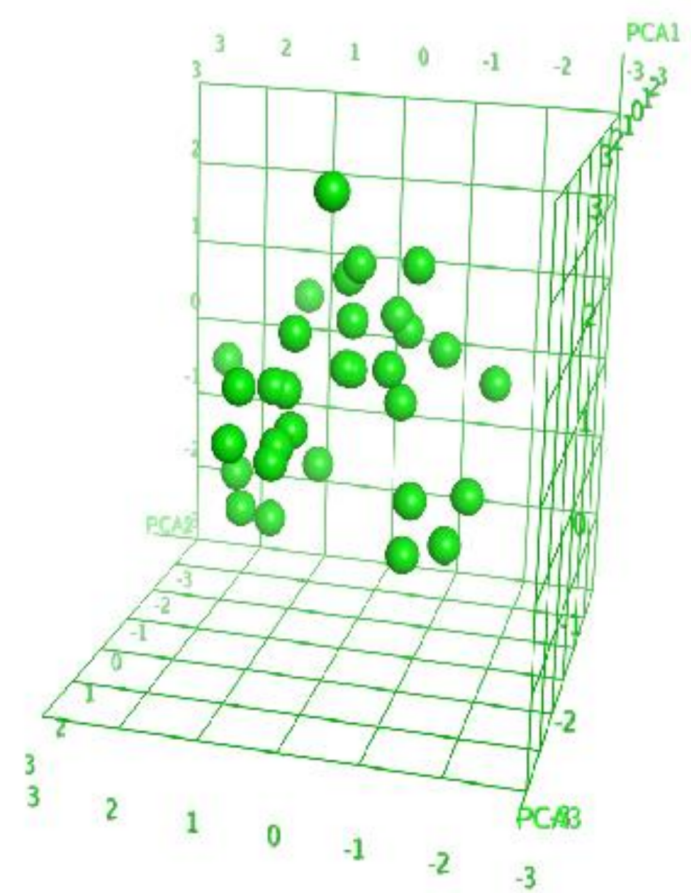

Figure 2. (A) 2D plots to visualize the variation of the three most important computed principal components for the training set (Blue box represent the outlier TH58) and (B) 3D visualization of the chemical space occupied by the training set molecules using the first three PCAs.

\subsection{Molecular Docking}

At the beginning of this study several co-crystallized protein-ligand structures of smHDAC8 were known and available in the protein databank (https:/ / www.rcsb.org/ (Accessed 16 January 2020)). The existence of these deposited complexes allowed the restriction of the molecules to be docked in the binding site only and the prior knowledge of reported ligand-target interactions/pose helped in selecting poses that are closest to the experimentally reported pose. As mentioned above, 25 crystal structures of $s m$ HDAC 8 in complex with various inhibitors were studied in the current work. The selection of the most suitable crystal structure for the docking protocol was based on re- and crossdocking studies.

Docking in protein structure PDB ID 6HRQ showed good re-docking results (Figure 3) as well as the best cross-docking results, where the docking poses of 21 out of 25 docked 
ligands showed an rmsd $\leq 2 \AA$ (Table S1). Failure to reproduce the docking pose of some of the crystal structure could be attributed to (i) a different ZBG (e.g., 4CQF had a thiol ZBG while other structures had a benzhydroxamate ZBG) (ii) different compound/linker class (e.g., while we were focused on reproducing the binding pose of amide or amine meta-substituted benzhydroxamates linkers, PDB Codes: 4BZ7 and 4CQF possess linear and flexible linkers lacking the aromatic portion while $6 \mathrm{HSH}$ had a heteroaromatic linker with two rings connected (2-(piperidin-1-yl)pyrimidine)).

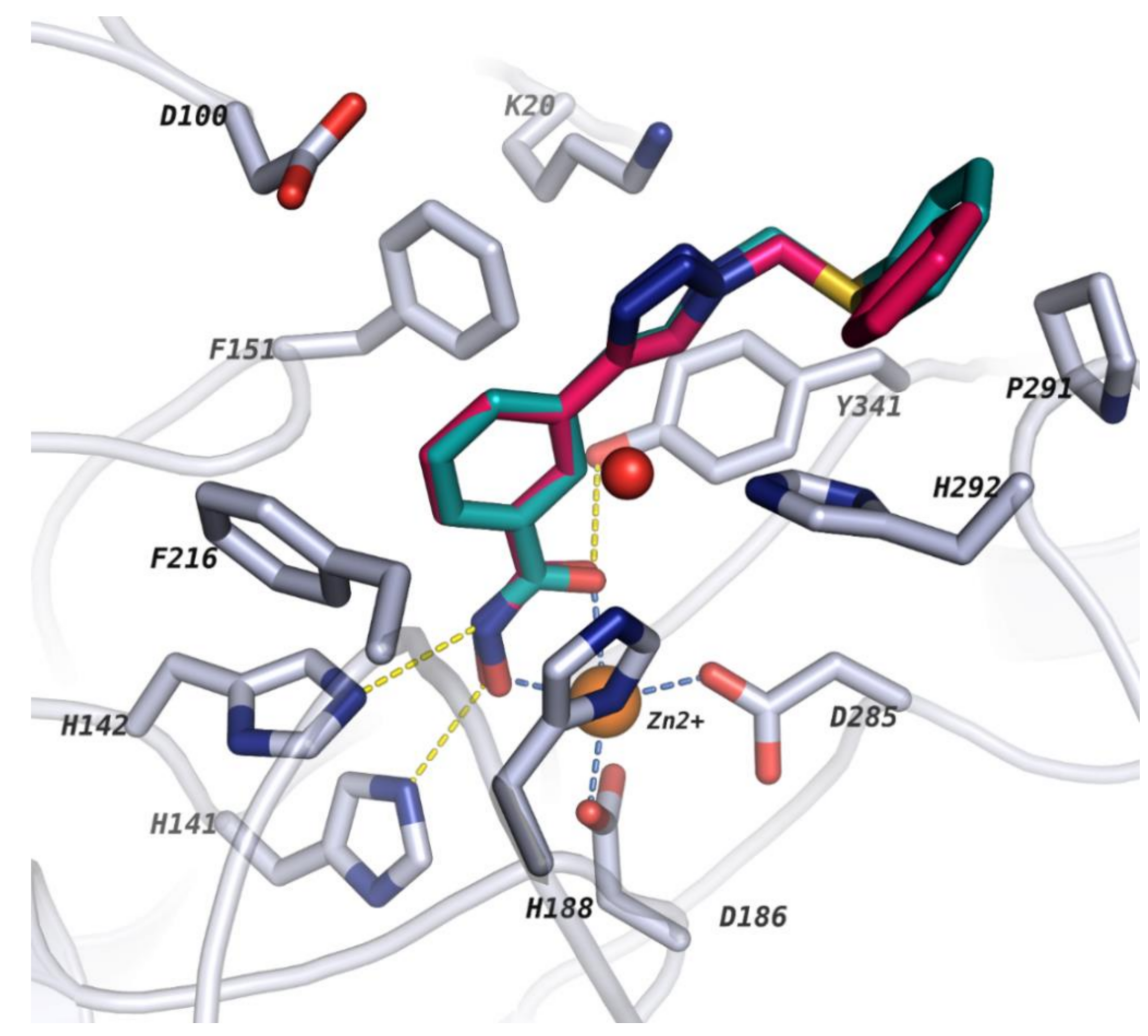

Figure 3. Re-docked pose in PDB code: 6HRQ. Crystallized ligand and re-docked ligand poses are shown in cyan and magenta, respectively. Protein backbone is shown as a cartoon (white ribbon) and side chains of key amino acid residues in the active sites are shown as white sticks. The catalytic zinc ion and conserved water molecule are shown as orange and red spheres, respectively.

In general, the chosen docking protocol could reproduce the experimentally determined binding mode of the already reported ligands with an rmsd $<2 \AA$ (Figure 4). In all cases, the hydroxamate group (ZBG) of the docked ligands coordinates the zinc ion in a bidentate manner as well as showing other interactions (such as the hydrogen bonds between the ligands and His141, His142, Lys20, His292 and Tyr341 residues in addition to $\pi-\pi$ staking interactions with residues lining the lysine binding tunnel and the side pocket) to stabilize the ligand-protein complex. Interestingly, based on our docking protocol, the selected poses were also top ranked using the standard precision (SP) scoring function of Glide in Schrödinger software. Hence, the top-ranked docking pose for each ligand was selected for further calculations after careful visual inspection. However, the correlation between the docking scores and the experimentally reported activities was poor $\left(\mathrm{r}^{2} \sim 0.009\right)$ (Model 1; Table 2; Table S1). Thus, the obtained docking poses were rescored by means of binding free energy calculations as discussed in the following section. 

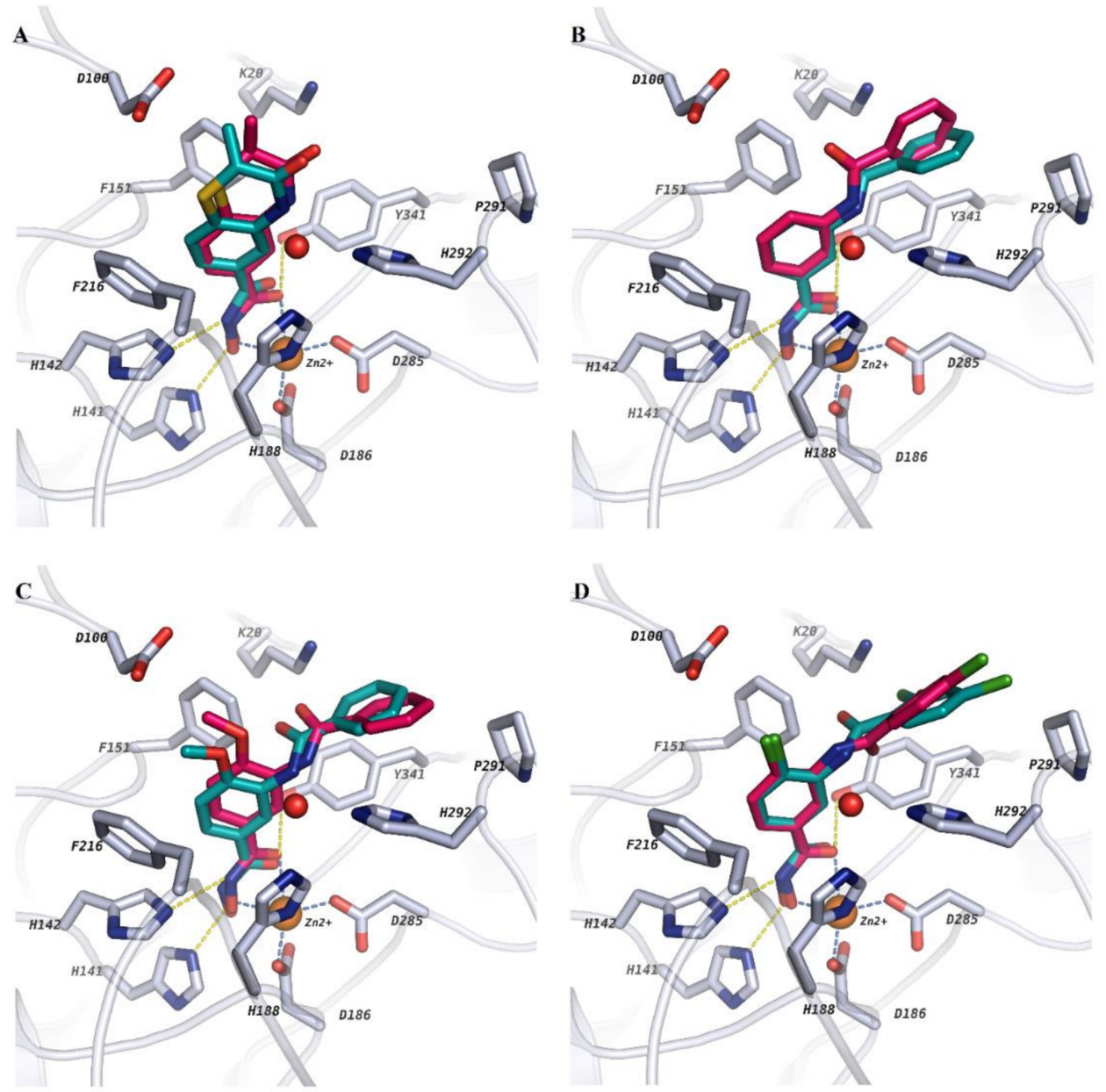

Figure 4. Comparing the docking poses derived from our docking protocol with the crystallized smHDAC8 ligands. Co-crystallized ligands were taken from the corresponding PDB IDs by overlapping (A) PDB ID: 4BZ8, (B) PDB ID: 5FUE, (C) PDB ID: 6HT8 and (D) PDB ID: 6HU1. Co-crystallized ligands with their experimentally determined binding mode are shown in cyan while the docking pose of the ligands from our docking protocol in PDB ID: 6HRQ are shown in magenta. In the different pictures, protein backbones are shown as ribbons and side chains of key amino acid residues in the active sites are shown as white sticks. Catalytic zinc ion and conserved water molecule are shown as orange and red spheres, respectively.

\subsection{Analysis of BFE}

Due to the low correlation $\left(\mathrm{r}^{2}\right)$ observed between the Glide-SP docking score and the experimentally determined activities, we further evaluated the affinities of the ligands to $s m$ HDAC8 using complex minimization and MM-PB/GBSA and QM/MM methods (using Amber software). The top scored docking poses from the molecular docking step were rescored either using a single frame (after short minimization steps) or several frames from the short MD simulations (1 ns). Different GB models, namely GB ${ }^{\mathrm{HCT}}$ (igb $=1$ ), $\mathrm{GB}^{\mathrm{OBC}}$ (igb = 2), $\mathrm{GB}^{\mathrm{OBC} 2}$ (igb = 5), and $\mathrm{GBn}$ (igb = 8), as well as PB_mbondi (mbondi), PB_bondi (bondi) and PB_Parse (PARSE) were used to estimate the BFE. Moreover, the hybrid QM/MM-GBSA approach was also implemented, where the ligand and the catalytic $\mathrm{Zn}^{2+}$ ions were treated as the QM region using Parameterized Model number 3 (PM3) and Austin Model 1 (AM1) semi-emperical Hamilitonian theories in combination with GB1 solvation [55-66].

As mentioned in Sections 3.3 and 3.4, models were generated using either the combination of terms summing up to the total energy term or the overall calculated energy. Furthermore, we tried to improve the quality of some of the models with the addition of a 
2D-descriptor (Fractional positive polar van der Waals surface area) computed in MOE. The fractional positive polar van der Waals surface area (PEOE_VSA_FPPOS) was chosen amongst other descriptors to observe how the overall charge property of the molecules can contribute to explaining the observed activity of the molecules. In summary, 126 models were generated based on the docking score, complex minimization as well as the different MMGB-PB/SA and QM/MM methods/models used. The obtained correlation results using the different methods are shown in the SI (Table S2). In Table 2, selected correlation results are listed to give an overview on the performance of the different methods. In general, BFEs from MM-PBSA using the PB-bondi radii averagely outperformed the other methods in explaining the reported experimental activities.

Table 2. Summary of statistical interpretation of the selected models.

\begin{tabular}{|c|c|c|c|c|c|c|c|c|c|c|c|c|}
\hline \multirow{2}{*}{$\begin{array}{l}\text { Model } \\
\text { Number }\end{array}$} & \multirow[t]{2}{*}{ Method } & \multirow[t]{2}{*}{ Frame } & \multirow{2}{*}{$\begin{array}{l}\text { Number of } \\
\text { Molecules }\end{array}$} & \multicolumn{2}{|c|}{$\operatorname{lm}$} & \multicolumn{2}{|c|}{ LOOCV } & \multicolumn{2}{|c|}{$\begin{array}{c}\text { Leave_3out } \\
\text { CV }\end{array}$} & \multicolumn{2}{|c|}{ 3fold CV } & \multirow[t]{2}{*}{ Outlier } \\
\hline & & & & $\mathbf{r}^{2}$ & RMSE & $q^{2}$ & QMSE & $q^{2}$ & QMSE & $q^{2}$ & QMSE & \\
\hline 1 & & & 34 & 0.01 & 0.44 & - & - & - & - & - & - & \\
\hline 6 & AM1/GB1 & Emin2 & 34 & 0.41 & 0.34 & 0.30 & 0.37 & - & - & - & - & \\
\hline 7 & AM1/GB1 & Emin2 & 34 & 0.51 & 0.31 & 0.38 & 0.35 & - & - & - & - & \\
\hline 22 & $\mathrm{~GB}^{\mathrm{HCT}}(\mathrm{igb}=1)$ & Emin2 & 34 & 0.31 & 0.37 & 0.13 & 0.42 & - & - & - & - & \\
\hline 23 & $\mathrm{~GB}^{\mathrm{HCT}}(\mathrm{igb}=1)$ & Emin2 & 34 & 0.51 & 0.31 & 0.32 & 0.36 & - & - & - & - & \\
\hline 33 & $\mathrm{~GB}^{\mathrm{OBC}}(\mathrm{igb}=2)$ & Emin1 & 33 & 0.30 & 0.37 & 0.19 & 0.40 & - & - & - & - & \\
\hline 34 & $\mathrm{~GB}^{\mathrm{OBC}}(\mathrm{igb}=2)$ & Emin1 & 34 & 0.46 & 0.32 & 0.33 & 0.36 & - & - & - & - & \\
\hline 48 & $\mathrm{~GB}^{\mathrm{OBC}}(\mathrm{igb}=5)$ & Emin1 & 34 & 0.31 & 0.36 & 0.20 & 0.40 & - & - & - & - & \\
\hline 49 & $\mathrm{~GB}^{\mathrm{OBC}}(\mathrm{igb}=5)$ & Emin1 & 34 & 0.47 & 0.32 & 0.34 & 0.36 & - & - & - & - & \\
\hline 65 & GBn $(i g b=8)$ & Emin2 & 34 & 0.19 & 0.40 & 0.02 & 0.48 & - & - & - & - & \\
\hline 77 & PB-mbondi & Emin2 & 34 & 0.27 & 0.38 & 0.08 & 0.43 & - & - & - & - & \\
\hline 94 & PB-bondi & $\begin{array}{l}\text { MD51- } \\
100\end{array}$ & 34 & 0.45 & 0.33 & 0.36 & 0.35 & 0.39 & 0.36 & 0.38 & 0.36 & \\
\hline 95 & PB-bondi & $\begin{array}{l}\text { MD51- } \\
100\end{array}$ & 34 & 0.61 & 0.27 & 0.53 & 0.30 & 0.55 & 0.30 & 0.54 & 0.31 & \\
\hline 96 & PB-bondi & $\begin{array}{l}\text { MD51- } \\
100\end{array}$ & 33 & 0.62 & 0.22 & 0.53 & 0.25 & 0.56 & 0.25 & 0.54 & 0.26 & TH58 \\
\hline 97 & PB-bondi & $\begin{array}{l}\text { MD51- } \\
100\end{array}$ & 31 & 0.73 & 0.19 & 0.66 & 0.22 & 0.70 & 0.21 & 0.69 & 0.22 & $\begin{array}{l}\text { TH58, } \\
\text { TH70, } \\
\text { TH74 }\end{array}$ \\
\hline 105 & PB-PARSE & Emin2 & 34 & 0.17 & 0.40 & 0.01 & 0.46 & - & - & - & - & \\
\hline 117 & PM3/GB1 & Emin2 & 34 & 0.37 & 0.35 & 0.26 & 0.38 & - & - & - & - & \\
\hline 118 & PM3/GB1 & Emin2 & 34 & 0.52 & 0.31 & 0.41 & 0.34 & - & - & - & - & \\
\hline
\end{tabular}

lm: linear model, LOOCV: Leave-one out cross validation, Leave_3out CV: Leave-3-out cross validation, 3fold CV: 3fold cross validation, PM3/GB1: Parameterized Model number 3 in combination with GB1 solvation, AM1/GB1: Austin Model 1 in combination with GB1 solvation, Emin2: single frame after the second energy minimization step, Emin1: single frame after the first energy minimization step, MD51-100: every fifth frame from the first frame frames for 51-100 during the MD simulation run.

\subsection{Derived QSAR Models and Their Validation}

As aforementioned, BFEs were computed using either a single frame from energy minimization or several frames from MD simulations. An application of the Partial least square (PLS) method was then applied to generate QSAR models based on the computationally estimated BFEs from the MM-PB/GBSA and QM/MM methods. For instance, in the MD simulation step, selected frames/snapshots (every fifth frame from the first frame for 1-50, 51-100 and 101-500 frames) were used to compute BFEs for the model development. The models were first constructed using various response variables (Y-variables) (1) the total calculated energy $\Delta G(2)$ the deltaGgas and deltaG $G_{\text {sol }}$ values that sum up to the total energy. However, these models generated based on the computed BFEs did not show sufficient correlation with the observed biological activities. In order to improve the performance, we also investigated the effect of considering further computed descriptors in combination with the estimated BFEs to explain the reported biological activities. Thus, resulting models developed in this study were developed with or without the computed 2D descriptor. 
The developed QSAR models used in this study are exemplified in Table 2 (the entire list of models is presented in Table S2). Overall, we constructed 126 models using the BFEs calculated at different steps. These models were developed using several approaches (please refer to Sections 2.3 and 3.3) so as to explore every means to explain variance in the observed activity of the molecules. Overall, models were judged based on their $\mathrm{r}^{2}$ and $\mathrm{q}^{2}$ values. For this study, better $\mathrm{r}^{2}$ and $\mathrm{q}^{2}$ values for the training set was observed with model 97 when compared to those from the initial "model 94"; both models generated using the PB-bondi radii. Model 97 was developed through the continuous improvement of model 94 (Table 2). The progress in the development of the topped model from each method utilized herein will be discussed in the following paragraphs with main focus on models 94 to 97 from MM-PBSA using the PB-bondi radii calculation.

We observed that all the models developed using MM-GBSA with $\mathrm{GB}^{\mathrm{HCT}}$ (igb =1), $\mathrm{GB}^{\mathrm{OBC}}(\mathrm{igb}=2), \mathrm{GB}^{\mathrm{OBC} 2}(\mathrm{igb}=5)$, and $\mathrm{GBn}(\mathrm{igb}=8)$ solvation models did not lead to satisfactory results and the computed BFEs were unable to explain the reported activity of the molecules in the training set. Just as observed in Table 2 above, the best model obtained using $\mathrm{GB}^{\mathrm{HCT}}$ (igb = 1) calculations was model 23 which was designed using the computed contributions of deltaG $\mathrm{G}_{\text {gas }}$ and $\mathrm{deltaG}_{\mathrm{sol}}$ at the second energy minimization step and including the 2D descriptor PEOE_VSA_FPPOS (Equation (1)). This model showed a correlation coefficient $\left(\mathrm{r}^{2}\right)$ of 0.51 and rmse of 0.3 . However, further statistical validation of the model using the LOOCV approach led to very low $\mathrm{q}^{2}$ and higher qmse; thus, the discarding of the model. Meanwhile, all models developed using GB2, GB5 and GB8 showed an $\mathrm{r}^{2}<0.5$.

$\mathrm{pIC}_{50 \_ \text {pred }}=2.21599-0.05272 *$ deltaGgas $-0.05911 *$ deltaG $_{\text {sol }}+12.20274 *$ PEOE_VSA_FPPOS

Application of the MM-PBSA method (using PB-bondi radii) led to the stepwise development of a satisfactory model which showed good correlation with the biological data and good cross validation results. First, model 94 was developed based on the computed BFE from the MD step using every fifth frame from the first frame for frames 51-100. Exploration of the model revealed that its predictive performance was only moderate, as it could explain only about $45 \%$ variance of the reported biological activity $\left(\mathrm{r}^{2}\right.$ of 0.45$)$ while having an rmse of 0.35 (Table 2; Equation (2)). Therefore, we analyzed the molecular properties of the studied inhibitors and calculated a variety of molecular descriptors and include them in the QSAR models. We identified PEOE_VSA_FPPOS; a 2D descriptor that improved the QSAR model (Model 95).

$$
\mathrm{pIC}_{50} \text { pred }=3.98023-0.03888 * \Delta \mathrm{G}
$$

Improvement of model 94 by including PEOE_VSA_FPPOS as a 2D descriptor led to model 95 (Equation (3)) which could better explain the correlation between the experimental and calculated activities. The $\mathrm{r}^{2}$ value was observed to increase from 0.45 (in model 94) to 0.61 (in model 95). In addition to the increased $\mathrm{r}^{2}$ values, $\mathrm{q}^{2}$ also increased from 0.36 to $0.53,0.39$ to 0.55 and 0.38 to 0.54 for LOOCV, Leave-3-out-CV, and 3fold-CV validations, respectively. This model was also considered to be more reliable because the rmse values were generally at acceptable limits (Figure 5).

$$
\text { pIC } 50 \_ \text {pred }=3.31705-0.03592 * \Delta \mathrm{G}+10.69909 * \text { PEOE_VSA_FPPOS }
$$




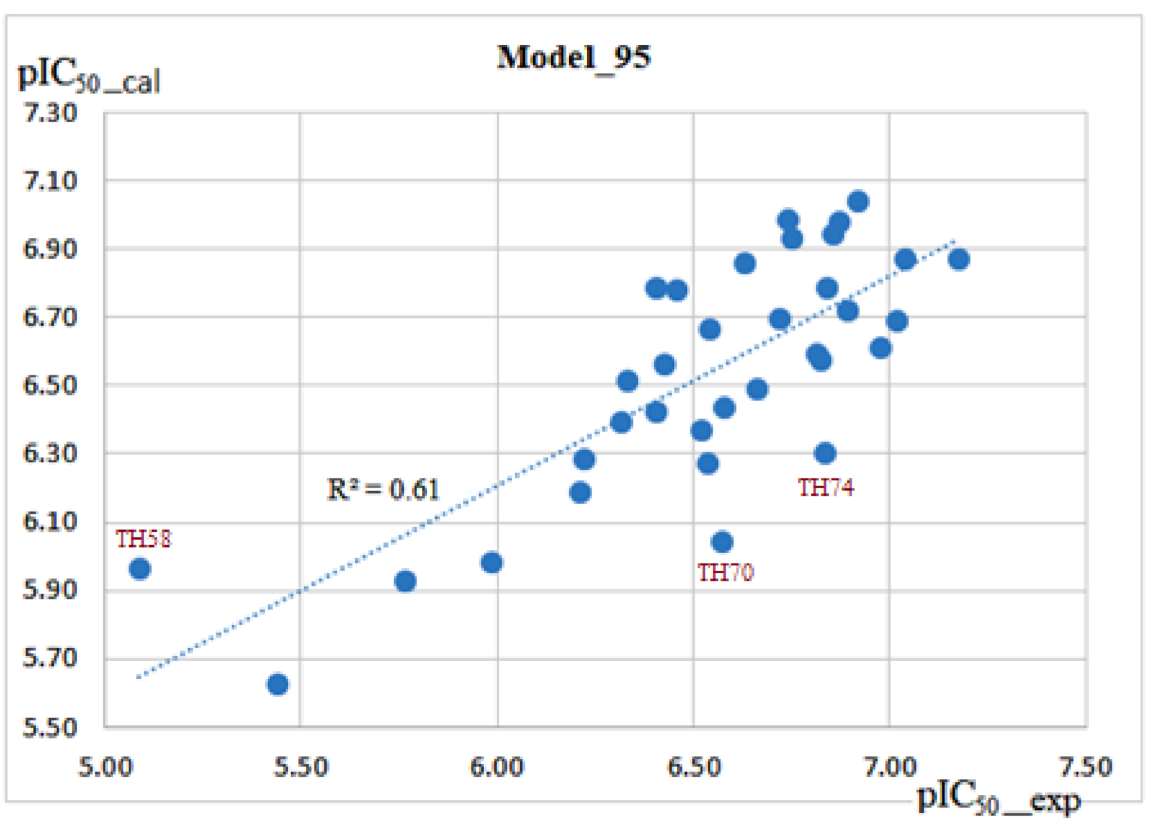

Figure 5. Correlation plot between the experimental $\mathrm{pIC}_{50}$ values $\left(\mathrm{X}\right.$-axis) and the calculated $\mathrm{pIC}_{50}$ values (Y-axis) for the training set molecules (blue points) using model 95.

Analyzing Model 95 detected three outliers based on their calculated Z-score (Z-score $>2$, compounds TH58, TH70 and TH74) and removal of these compounds led to the development of Model 97 (Equation (4), Figure 6) with a significant difference in the $\mathrm{r}^{2}$, $\mathrm{q}^{2}$, rmse and qmse values when compared with model 95 . Z-score in brief represents the absolute difference between the experimentally reported value and the predicted value base on the model in question divided by the square-root of the mean square error of the dataset. Z-scores were calculated for the molecules in this study using the QSAR module of MOE and molecules with Z-score greater than two were considered outliers. In addition to the statistical Z_score that was used to select molecules that were deemed as outliers, compounds TH58 and TH70 were further considered outliers based on the following observations/analyses. From another point of view, the computed 2D-descriptors to analyze the chemical space of the molecules could also be used to explain why TH58 was an outlier. For instance, based on the chemical space analysis, TH58 occupied a distant chemical space when compared to other molecules within the training set and it was thus not strange having it in the list of outliers. TH70 on the other hand, although structurally similar to molecules of scaffold $\mathrm{B}$, had the $\mathrm{N}$-atom of the linker portion of the molecule replaced with an O-atom. This difference in atom type brought about observable changes in docking pose for compound TH70 when compared with a structurally related compound (TH28). The docking pose of compound TH70 showed that some important interactions including the hydrogen bond interaction observed between the docked molecules with His 292 and Lys20 were missing. Additionally, a slight change in the coordinate of the aromatic linker was observed. The resulting model could explain $\sim 73 \%$ variation of the reported experimental activity (Figure 6). For this reason, model 97 was also considered for further investigation and prediction of novel designed $s m$ HDAC8 inhibitors. 


$$
\mathrm{pIC}_{50 \_ \text {pred }}=3.45878-0.03231 * \Delta \mathrm{G}+11.84528 * \text { PEOE_VSA_FPPOS }
$$

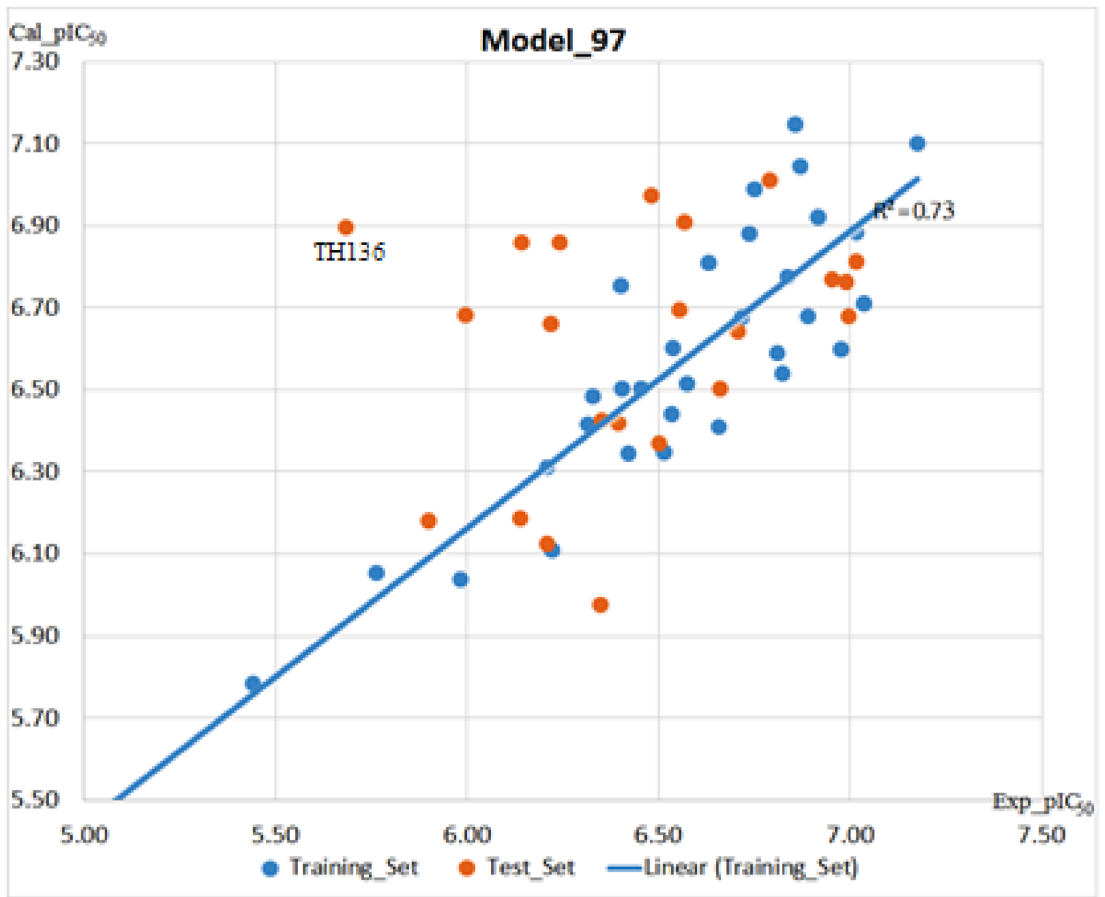

Figure 6. Correlation plot between the experimental $\mathrm{pIC}_{50}$ values $\left(\mathrm{X}\right.$-axis) and the calculated $\mathrm{pIC}_{50}$ values (Y-axis) for the training set molecules (blue points) using model 97 as well as the distribution of the newly designed set of molecules (orange points) along the linear regression line.

\subsection{Evaluation of Novel Designed smHDAC8 Inhibitors}

To further evaluate the reliability and predictive power of the best performing models, the best models were evaluated on a set of newly developed inhibitors (Figure 7, Table 3). Based on the obtained biological data of the previously described molecules in the training set, we utilized a structure-based approach in order to design further benzhydroxamate derivatives in an attempt to optimize their activity against smHDAC8. Generally, the scaffolds (scaffold A and B) were maintained (except for an inverse amide derivative, compound 23) while the substituents at the para- $\left(R_{1}\right)$ and meta- $\left(R_{2}\right)$ positions were altered. The maintained scaffolds have well established interactions with important amino acids such as Tyr304, His292, His140, His141, Lys20 as well as a bidentated coordination to the catalytic zinc ion; as seen in solved $\operatorname{smHDAC} 8$ crystal structures. For instance, starting from the lead compounds TH61 and TH39 including several derivatives which bear an additional alkoxy substituent at the 2- and 2,4-positions of the phenyl capping group were designed, with the goal of better addressing the hydrophobic side pocket. This improved Van der Waals interactions led to increased activity as seen when moving from TH66 to TH92. This observation led to the exploration of several hydrophobic substituents including the effects of bicyclic and tricyclic substituents. Docking pose prediction for such compounds showed that they could fit within the receptor active site while maintaining the necessary interactions from the scaffolds used. Thus, derivatives which have bulkier aromatic substituents at the 3- and 4-positions of the phenyl capping group, such as the biphenyl and phenoxyphenyl derivatives (TH77 and TH95) were further modified by adding different substituents at the m-position of the benzhydroxamte moiety. Compound TH60, possessing a quinolyl moiety as a capping group, was another inhibitor within the training set which showed highly potent inhibition of $s m$ HDAC8. Hence, further derivatives with bi- and tricyclic capping groups, such as compounds 2, 6, 7, 18, 19 and 
20, were designed and synthesized (details on the synthesis, crystallization and biological testing will be published elsewhere).

Analysis of the chemical space of the designed (test set) molecules in a similar way as for the training set revealed that the designed inhibitor $\mathbf{2 4}$ distanced itself from the remaining molecules (Figure 7 while the 2D and 3D distribution of the molecules can be seen in Figures 8 and 9). Figure 9 shows that the computed properties of this molecule do not fall in line with the properties of the molecules designed based on the scaffolds (scaffold A and B) of choice for this study. To further visualize the position of the molecules used in this study, we performed extra graphical representation as seen in Figure 9. With the exception of compound $\mathbf{2 4}$ in the newly designed/external set, all the molecules were homogeneously distributed within the PCA space. Thus, the molecules used in this study generally occupied a similar chemical space. In addition to this observation, we could also explain the position of compound $\mathbf{2 4}$ as an outlier, based on the fact that this compound uniquely has a carboxylate substituent at the meta-position of the benzhydroxamate scaffold (Figures 7 and 9) which plays a role in deviating its computed properties from the rest of the molecules.<smiles>[R]C(=O)Nc1cc(C(=O)NO)ccc1[R]</smiles>

Scaffold A<smiles>[R]Nc1cc(C(=O)NO)ccc1[R]</smiles>

Scaffold B<smiles>O=C(NO)c1cccc(C(=O)Nc2ccccc2)c1</smiles>

23<smiles>O=C(O)c1cccc(C(=O)NO)c1</smiles>

24

Figure 7. Chemical structures of novel $s m$ HDAC8 inhibitors used as external test set. 
Table 3. Chemical structure and prediction of test set compounds.

\begin{tabular}{|c|c|c|c|c|c|c|c|c|c|c|}
\hline $\begin{array}{l}\text { Compound } \\
\text { Number }\end{array}$ & $\begin{array}{l}\text { Compoud } \\
\text { Code }\end{array}$ & Scaffold & $\mathbf{R} 1$ & $\mathbf{R} 2$ & $\begin{array}{c}\text { smHDAC8_IC } \\
\text { nM- }\end{array}$ & pIC $50 \_\exp$ & $\mathrm{pIC}_{50 \_ \text {pred }}$ & $\begin{array}{c}\text { Res }^{\mathrm{a}} \\
\left(\text { Exp_pIC }_{50^{-}}\right. \\
\left.\text {Pred_pIC }{ }_{50}\right)\end{array}$ & $\begin{array}{c}\text { Res }^{b} \\
\text { Avg_Exp_pIC } \text { fo- }^{-} \\
\text {Pred_pIC } 50\end{array}$ & $\begin{array}{l}\text { Glide } \\
\text { SP_Score }\end{array}$ \\
\hline 1 & AT_T4 & A & methoxy & $\begin{array}{l}\text { 9H-fluoren-1-yl } \\
\text { 3-methyl-1,2,3,4- }\end{array}$ & $163 \pm 17$ & 6.79 & 7.01 & -0.22 & -0.44 & -9.20 \\
\hline 2 & SD14 & $\mathrm{A}$ & methoxy & $\begin{array}{c}\text { tetrahydro-Y-carbolin- } \\
8 \text {-yl }\end{array}$ & $197 \pm 19$ & 6.71 & 6.64 & 0.06 & -0.07 & -9.24 \\
\hline 3 & TH112 & A & ethoxy & 2,4-dichlorophenyl & $103 \pm 7$ & 6.99 & 6.77 & 0.22 & -0.20 & -8.99 \\
\hline 4 & TH117 & A & chloro & 4-biphenyl & $404 \pm 90$ & 6.39 & 6.42 & -0.03 & 0.15 & -8.69 \\
\hline 6 & TH120 & A & chloro & benzo[b]thien-7-yl & $97 \pm 16$ & 7.01 & 6.81 & 0.20 & -0.24 & -8.90 \\
\hline 7 & TH125 & A & methoxy & $\begin{array}{c}\text { 1H-benzo[d]imidazol- } \\
\text { 2-yl }\end{array}$ & $575 \pm 72$ & 6.24 & 6.86 & -0.62 & -0.29 & -9.48 \\
\hline 8 & TH127 & A & methoxy & 3-benzyloxyphenyl & $605 \pm 68$ & 6.22 & 6.66 & -0.44 & -0.09 & -9.23 \\
\hline 9 & TH128 & A & methyl & 3-benzyloxyphenyl & $447 \pm 31$ & 6.35 & 6.43 & -0.08 & 0.14 & -8.63 \\
\hline 10 & TH132 & A & methoxy & 2-chloro-4-biphenyl & $101 \pm 77$ & 7.00 & 6.68 & 0.31 & -0.11 & -8.71 \\
\hline 11 & TH133 & A & chloro & 2-chloro-4-biphenyl & $112 \pm 11$ & 6.95 & 6.77 & 0.18 & -0.20 & -8.35 \\
\hline 12 & TH134 & A & methoxy & 4-propoxyphenyl & $729 \pm 86$ & 6.14 & 6.19 & -0.05 & 0.38 & -8.51 \\
\hline 13 & TH135 & A & methoxy & 4-isopropoxyphenyl & $725 \pm 52$ & 6.14 & 6.86 & -0.72 & -0.29 & -8.76 \\
\hline 15 & TH137 & A & chloro & 2,4-dimethoxyphenyl & $220 \pm 13$ & 6.66 & 6.51 & 0.15 & 0.06 & -9.22 \\
\hline 16 & TH138 & $\mathrm{A}$ & methoxy & $\begin{array}{l}\text { 2-chloro-4-(4- } \\
\text { fluorophenyl)phenyl }\end{array}$ & $318 \pm 19$ & 6.50 & 6.37 & 0.13 & 0.20 & -8.99 \\
\hline 17 & TH139 & A & chloro & $\begin{array}{l}\text { 2-chloro-4-(4- } \\
\text { fluorophenyl)phenyl }\end{array}$ & $281 \pm 37$ & 6.55 & 6.70 & -0.14 & -0.13 & -8.66 \\
\hline 18 & TH142 & A & methoxy & quinolin-8-yl & $332 \pm 51$ & 6.48 & 6.98 & -0.50 & -0.41 & -9.84 \\
\hline 19 & TH143 & A & methoxy & 4-dibenzofuranyl & $271 \pm 30$ & 6.57 & 6.91 & -0.34 & -0.34 & -9.76 \\
\hline 20 & TH156 & B & methoxy & 4-dibenzofuranyl & $451 \pm 90$ & 6.35 & 5.98 & 0.37 & 0.59 & -9.42 \\
\hline 21 & TH34 & B & methyl & benzyl & $1260 \pm 170$ & 5.90 & 6.18 & -0.28 & 0.39 & -9.15 \\
\hline 22 & TH42 & B & methoxy & benzyl & $620 \pm 0$ & 6.21 & 6.13 & 0.08 & 0.44 & -9.74 \\
\hline 23 & TH97 & - & - & - & $220 \pm 67$ & 6.66 & 6.77 & -0.11 & -0.26 & -8.13 \\
\hline 24 & TH98 & - & - & - & $1590 \pm 190$ & 5.80 & 6.49 & -0.69 & 0.08 & -9.59 \\
\hline
\end{tabular}

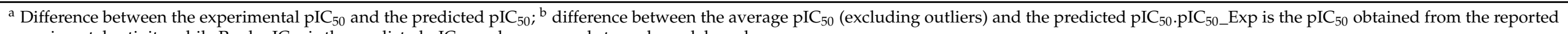
experimental activity while Pred_pIC 50 is the predicted $\mathrm{pIC}_{50}$ and corresponds to each model used. 


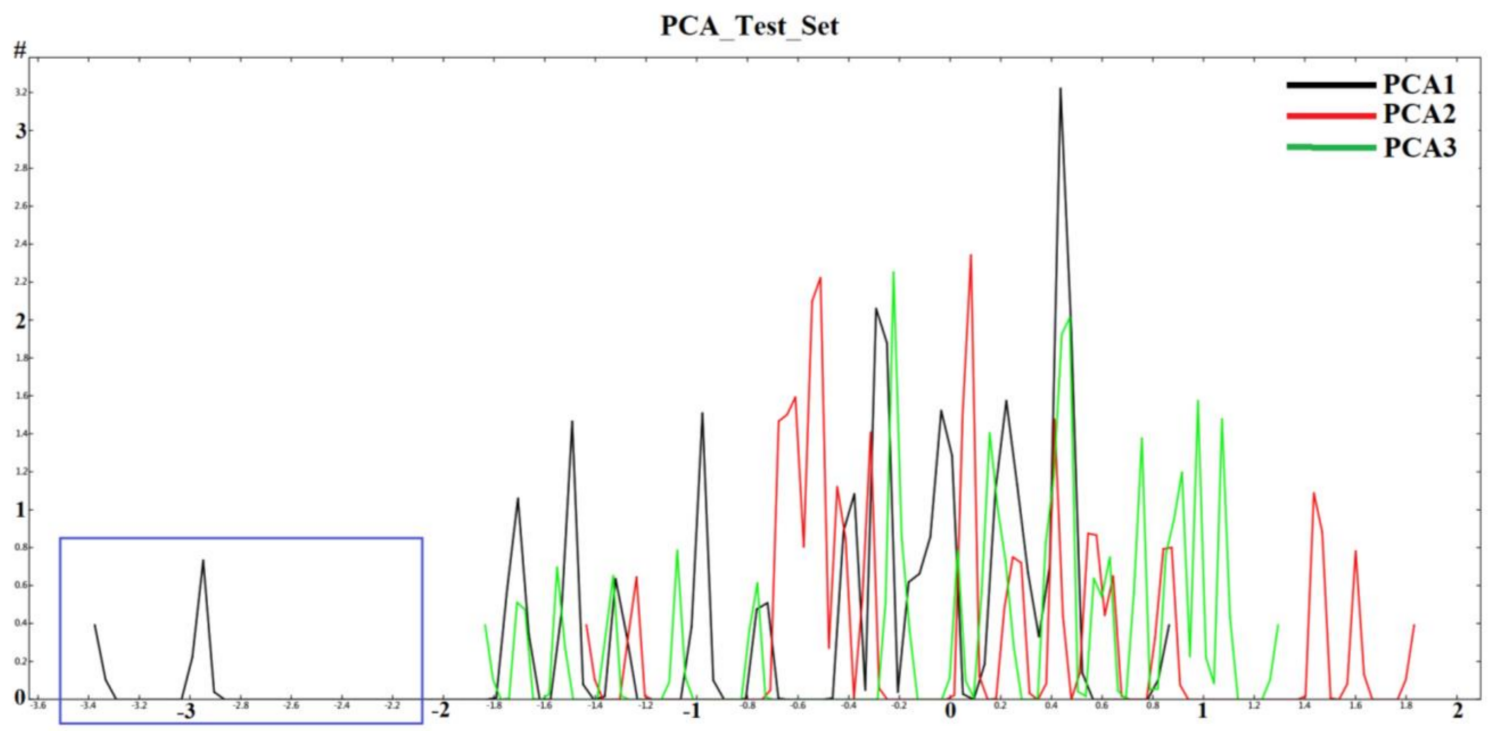

Figure 8. 2D plots to visualize the variation of the three most important computed principal components for the test set (Blue box represent the outlier; compound 24).

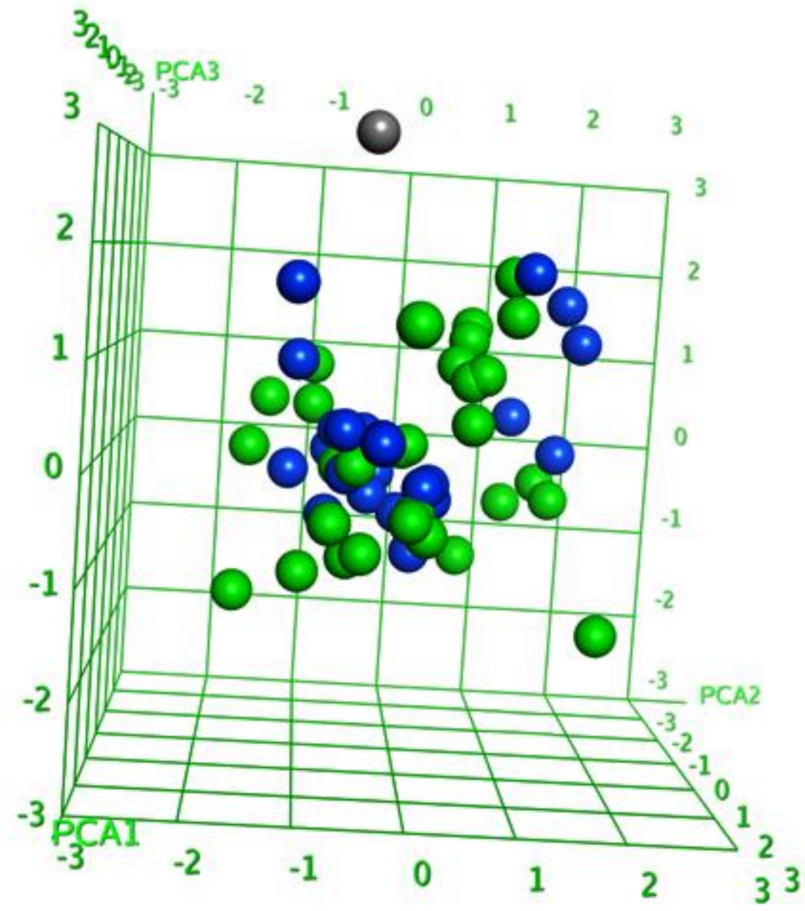

Figure 9. 3D visualization of the first three PCAs to compare the chemical space occupied by training set (green balls) and newly designed molecules (blue balls) while the outlier (compound 24) from the newly designed set is shown as the grey ball. 
In order to predict the activity of the newly designed (test set) molecules, docking and BFE calculations were also performed following the same protocols reported for the training set. Additionally, due to the good performance of Models 95, 96 and 97 (judging by the observed $\mathrm{r}^{2}$ and $\mathrm{q}^{2}$ values between experimental and predicted $\mathrm{pIC}_{50}$ values from the training set molecules; for predictions from Models 95 and 96, see Table S3), the three models were considered for the final prediction of activities of the newly designed molecules. We assessed the predictive quality of the selected models by calculating the difference between the experimentally determined and predicted $\mathrm{pIC}_{50}$ values. The $\mathrm{IC}_{50}$ values of the newly designed and synthesized compounds were measured using a similar procedure as described in previous publications [49,67]. The observed experimental activity was in the sub-micromolar to lower-micromolar range (Table 3 ). The $\mathrm{IC}_{50}$ values were subsequently converted to $\mathrm{pIC}_{50}$ for further evaluations. For the vast majority of the newly designed set of compounds, the absolute difference between the experimental and predicted $\mathrm{pIC}_{50}$ values was $<0.7 \log$ unit (which is less than $1000 \mathrm{~nm}$ ) when considering all selected models. The low residual value between the experimentally measured activities and the predicted activities indicate that the models generated have good predictive ability.

However, all top models failed to rightly predict the activity of one out of the 25 newly designed molecules (compound 14; Figure 10, respectively), which showed weak experimental activity but was predicted to be highly active. Though there are no significant features setting this molecule apart from the rest of the molecules that were rightly predicted, it may be noted that this molecule possesses a capping group that could adopt different docking poses (Figure 11). Several docking poses were suggested for this molecule, with observable shift in coordinates of the atoms encompassing the capping group. Conversely, a detail look into the computed BFE and the different contributions summing-up to the total energy did not also show any abnormality. Thus, the model just failed to rightly predict this molecule, for reasons that are still to be identified. Looking at the residual between the average value of experimentally reported $\mathrm{pIC}_{50}$ of the training set that was used in generating model 97 and the predicted activity for each compound showed that $\sim 99 \%$ of the molecules were rightly predicted. The distribution of the molecules along the regression line (Figure 6) confirmed that the predictions generally had deviations less than $400 \mathrm{~nm}$.<smiles>COc1ccc(C(=O)Nc2cc(C(=O)NO)ccc2OC)c(OC)c1</smiles>

\section{4}

Figure 10. Structure of the poorly predicted molecule by Model 97. 


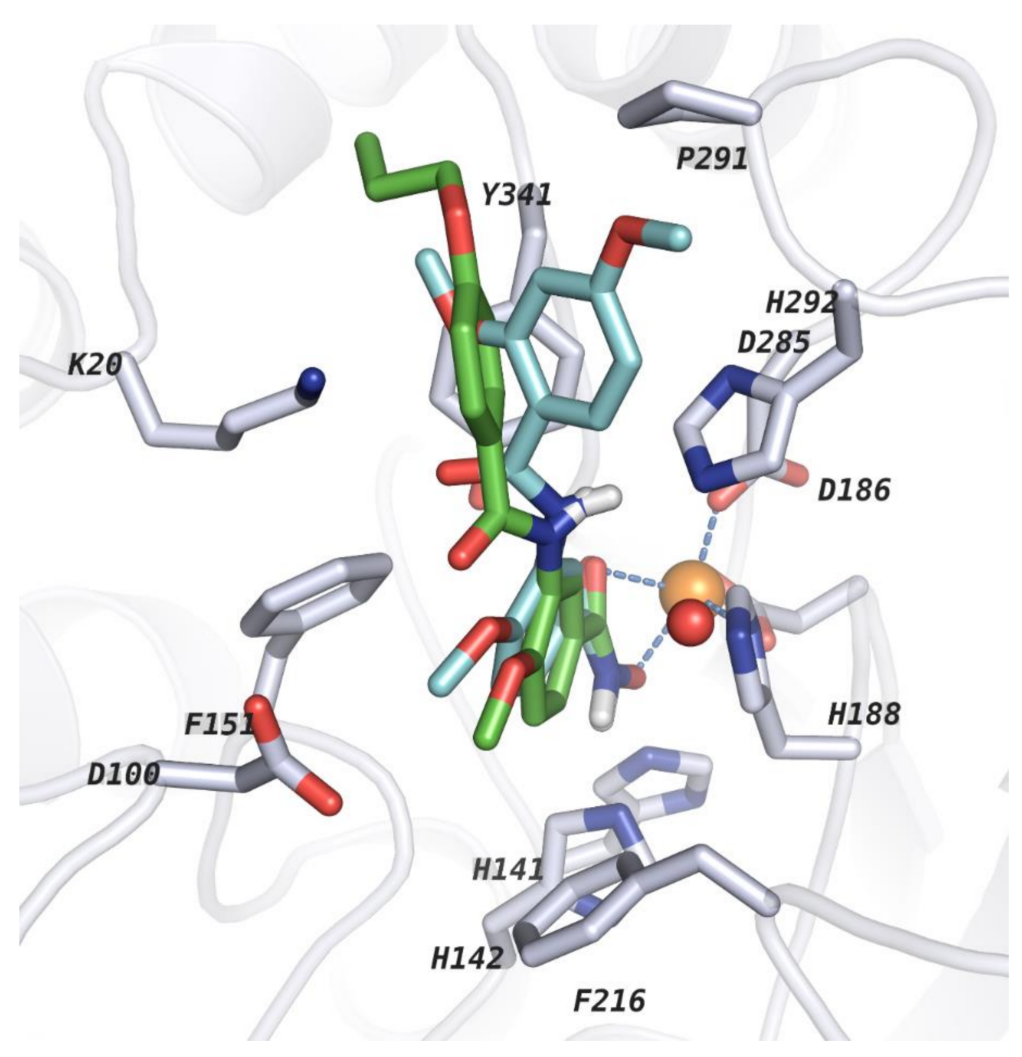

Figure 11. Comparison of the topped docking pose for the poorly predicted molecule (compound 14; cyan) with a closely related molecule (compound 12; green). Protein backbone is shown as ribbon and side chains of key amino acid residues in the active sites are shown as white sticks. Catalytic zinc ion and conserved water molecule are shown as orange and red spheres, respectively.

\section{Materials and Methods}

\subsection{Dataset Source, Preparation and Analysis}

\subsubsection{Dataset}

A set of 34 previously reported $s m$ HDAC8-inhibitors with their $s m$ HDAC8 IC $_{50}$ values were used as the training set for this study (Figure 1) [54]. All compounds were synthesized as reported [54], and the in vitro inhibitory activities were determined using an enzymatic assay. The measured $\mathrm{IC}_{50}$ values were converted to $\mathrm{pIC}_{50}$ values for the QSAR study.

\subsubsection{Calculation of Molecular Descriptors and Dataset Diversity Analysis}

Descriptors used in this work were calculated using MOE version 2016.08 [68]. Several 2D structural molecular descriptors for the training set and the newly designed series of benzhydroxamate derivatives were calculated. The calculated descriptors were further analyzed to ensure that there is no correlation between the descriptors using QuSARContingency (a statistical application in MOE), and the resulting descriptors were submitted for further utilization in this work (Table 4). To investigate the chemical space coverage (diversity) of the molecules used in this study, we applied the PCA method implemented in the MOE package. The selected descriptors were transformed linearly using PCA $[69,70]$. This resulted in a new (smaller) table of descriptors that are uncorrelated and normalized (mean $=0$ and variance $=1$ ). Analysis of the variation of percentage counts and the 2and 3-dimensional plots of the best three principal components (PCA1, PCA2 and PCA3) for all the datasets employed in this study was performed to check the diversity of the different sets. 
Table 4. List of selected 2D descriptors used to analyze the chemical space of molecules employed in this study.

\begin{tabular}{|c|c|}
\hline Notation & Molecular Descriptors \\
\hline a_heavy & Number of heavy atoms \\
\hline b_1rotN & Number of rotatable single bonds. Conjugated single bonds are not included \\
\hline b_single & $\begin{array}{c}\text { Number of single bonds (including implicit hydrogens). Aromatic bonds are not considered to } \\
\text { be single bonds. }\end{array}$ \\
\hline lip_acc & The number of $\mathrm{O}$ and $\mathrm{N}$ atoms. \\
\hline lip_don & The number of $\mathrm{OH}$ and $\mathrm{NH}$ atoms. \\
\hline $\mathrm{mr}$ & Molecular refractivity (including implicit hydrogens). \\
\hline PEOE_VSA_POL & The number of $\mathrm{OH}$ and $\mathrm{NH}$ atoms. \\
\hline TPSA & $\begin{array}{c}\text { Polar surface area ( } \mathrm{A} 2) \text { calculated using group contributions to approximate the polar surface } \\
\text { area from connection table information only. }\end{array}$ \\
\hline h_logD & The octanol/water distribution coefficient at $\mathrm{pH} 7$. \\
\hline PEOE_VSA_FPPOS * & Fractional positive polar van der Waals surface area. \\
\hline
\end{tabular}

* Included in some of the developed QSAR models for quality improvement.

\subsection{Molecular Docking}

\subsubsection{Ligand Preparation}

The ligands used in this study were prepared using a similar approach as we previously reported, and which was successful in reproducing the X-ray structures of smHDAC8inhibitor complexes [52,71]. We started with the generation of 3D structures of the inhibitors using MOE 2016.08 [68]. The generated molecules were further processed using the "Wash" option implemented in MOE to deprotonate strong acids and protonate strong bases. The resulting dataset, containing the ligands only in their hydroxamate form, was subsequently prepared for docking using the LigPrep tool as implemented in Schrödinger's software (version 2017-1) [72]. In this step, the generated ionization state obtained from MOE was kept; all possible tautomeric forms as well as stereoisomers were generated after which an initial structural energy minimization was performed using the integrated Optimized Potentials for Liquid Simulations 2005 (OPLS-2005) force field [73]. Finally, the ConfGen module also implemented in the Schrödinger's software package was used to generate 50 conformers of the prepared molecules while allowing minimization of the output conformations [74,75].

\subsubsection{Protein Preparation}

We used the same preparation protocol as in our earlier publications [50,52,54,71]. At the time of this work, 25 of the 28 published crystal structures for $\operatorname{smHDAC} 8$ were used (we excluded PDB Codes: 6HSF and 6HSG because they had mutated residues (from the schistomal His-292 residue to the human MET-292 residue) while PDB Code: 4BZ5 was excluded because it lacked a crystallized ligand). All crystal structures of $\operatorname{smHDAC} 8$ were imported into MOE from the PDB database (www.rcsb.org (Accessed 16 January 2020) $[68,76]$. For each crystal structure, all water molecules (except the conserved water molecule (HOH744) within the catalytic pocket that was used for the docking procedures) were deleted. The Protein Preparation Wizard of Schrödinger software was subsequently used for further preparations of the protein structure $[77,78]$. At this juncture, bond orders were assigned and hydrogen atoms added. Additionally, the hydrogen bond network was optimized and the protonation states at $\mathrm{pH} 7.0$ were predicted using the Epik-tool in Schrödinger [79,80]. Finally, a restrained energy minimization step (rmsd of the atom displacement for terminating the minimization was $0.3 \AA$ ) using the OPLS-2005 force field was performed on the system [73].

\subsubsection{Grid Generation and Docking}

For the 25 prepared protein structures, a receptor grid for each protein structure was generated using the receptor grid preparation module implemented in Schrödinger. In this step, the center of the co-crystallized ligand for each crystal structure corresponded to the centroid of the grid box. Additionally, a metal constraint to the conserved catalytic 
zinc metal ion was included while keeping other options as default. The docking protocol using Glide in the standard precision mode (SP-score) was first validated by (1) redocking (its ability to reproduce the binding mode of a co-crystallized ligand with the binding site of its crystalized protein) and (2) cross-docking (the ability to rightly predict the binding mode of ligands from other $s m$ HDAC 8 crystal structures). The entire re-docking and cross docking results are provided as a supplementary file. The best generated protocol, with PDB Code: $6 \mathrm{HRQ}$ (being able to reproduce the crystallized ligands poses with low rmsd) was then used to dock the prepared training set ligands using Glide [81-83]. A total of 20 poses per ligand conformer were included in the post-docking minimization step. The top-ranked docking pose for each ligand was selected and submitted for protein-ligand interactions (BFE analysis).

\subsection{Binding Free Energy (BFE) Calculations}

The obtained top-ranked docking poses were subjected to BFE calculations using different radii sets $\left(\mathrm{GB}^{\mathrm{HCT}}\right.$ (igb =1), $\mathrm{GB}^{\mathrm{OBC}}(\mathrm{igb}=2), \mathrm{GB}^{\mathrm{OBC}}$ (igb = 5), and $\mathrm{GBn}(\mathrm{igb}=8)$; Poison Boltzmann mbondi, bondi and PARSE), with the Tip3P solvation method and 12-6-4LJ ion model [84-88]. Preparation of ligands, protein, complexes and calculation methods employed in this step of the study are similar to those previously reported and are briefly described in the following sub-sections [89].

\subsubsection{Ligand and Ligand-Protein Complex Preparation}

Antechamber package in AMBER16 was used to prepare the top-ranked docking pose for each ligand using the semi-empirical Austin Model 1 (AM1) with Bond Charge Correction (BCC) (AM1-BCC) [90]. In this process, assignment of atom type, bond type, judging of the atomic equivalence, generation of residue topology file, as well as finding missing force field parameters and supplying reasonable and similar substitutes with the parmchk function of amber were done. The tleap module in AMBER was then used to prepare the various protein-ligand complexes.

Hydrogen atoms were added to all amino acid residues assuming a normal ionization state for all ionizable residues. The Duan et al. (2003) force field (ff03.r1) and general amber force field (gaff) were used for protein and ligand optimization, respectively [91-93]. TIP3P water solvation model was used to solvate the systems in an octahedral box, leaving at least $10 \AA$ A between the solute atoms and the borders of the box [85]. We also applied 12-6-4LJ ionic models for the zinc ion [94]. Additionally, $15 \mathrm{Na}^{+}$ions were required to neutralize each complex system.

The GPU-accelerated version (the accelerated version of the graphical processing unit) of the pmemd (pmemd.cuda) script in AMBER16 was used to run our pre-BFE calculations $[95,96]$. First, the solvated complexes were energy minimized using a 4000cycle minimization in two steps; ( 2000 cycles of steepest descent followed by 2000 cycles of a conjugate gradient) with restraints (force constant of $10 \mathrm{kcal}^{*} \mathrm{~mol}^{-1 *} \AA^{-2}$ ) on the protein, zinc and ligand atoms, while the solvent molecules and counter-ions were free. A further 4000 cycles (2000 cycles of steepest descent followed by 2000 cycles of a conjugate gradient) minimization without restraints of the entire systems was performed to remove any steric clash in the initial geometry of the protein. Subsequently, the system was heated over 100 ps from 0 to $300 \mathrm{~K}$ while restraining the solute (force constant of $10 \mathrm{kcal}^{*} \mathrm{~mol}^{-1 *} \AA^{-2}$ ) and the density then evaluated. An equilibration step over a period of $200 \mathrm{ps}$ was launched to equilibrate the systems before the MD step. Afterwards, a 1-ns MD simulation with a time step of 2 fs was applied using the Particle Mesh Ewald method [97,98]. During the equilibration and MD steps, the systems were kept at constant temperature of $300 \mathrm{~K}$ regulated with a Langevin thermostat with a collision frequency of $2 \mathrm{ps}^{-1}$ and pressure of 1 bar maintained using isotropic position scaling with a relaxation time of $2 \mathrm{ps}$. The SHAKE algorithm was applied to constrain all bonds involving hydrogens. Frames were written every 0.002 ns. Finally, a third energy minimization process using 4000 cycles (2000 cycles of steepest descent followed by 2000 cycles of a conjugate gradient) of the free systems 
after the MD step was performed. Snapshots for analysis were written every $2 \mathrm{fs}$ and the CPPTRAJ program inbuilt in AMBER16 was used to analyze the systems. A nonbonded cutoff distance of $10 \AA$ was used in all steps.

\subsubsection{MM-PB/GBSA and QM/MM Based BFE Prediction}

To estimate the respective binding free energies of the docked molecules against smHDAC8, molecular mechanics Poisson-Boltzmann/Generalized-Born Surface Area (MM-PB/GBSA) and the merged Quantum Mechanics/Molecular Mechanics (QM/MM) calculations were performed using the AMBER16 simulation package [90]. The MMPBSA.py script which utilizes the trajectory of complex only to create ensemble average of both the receptor and the ligand was used to estimate the BFE for each ligand-protein complex [99]. Various MM-PB/GBSA methods using different GB models, namely GB ${ }^{\mathrm{HCT}}$ (igb = 1), $\mathrm{GB}^{\mathrm{OBC}}(\mathrm{igb}=2), \mathrm{GB}^{\mathrm{OBC} 2}(\mathrm{igb}=5)$, and GBn (igb = 8), as well as the MM-PBSA method with different bond radii (bondi and PARSE) were utilized [55-66]. Additionally, the semiempirical methods including Parameterized Model number 3 (PM3) and Austin Model 1 (AM1) in combination with the GB1 solvation model were used in the hybrid QM/MM step to estimate the interaction energy between the receptor and ligand $[61,62,100,101]$. In this QM/MM approach, QM potentials were applied on the ligand and catalytic $\mathrm{Zn}^{2+}$ ion (constituting part of the receptor) while we apply MM force fields to remain part of the ligand-protein complex system. For the different methods listed, BFEs were computed at various stages of our protocol as described in Section 3.3.1, i.e., after each energy minimization step (Emin1 output structure of first minimization step used, Emin2: output frame of second minimization step used, and Emin3: output structure of minimization step of MD simulation last frame) and over different intervals of the MD simulation step (MD_p1; 1 to 50, MD_p2: 51 to 100 and MD_p3: 101 to 500 frames).

Generally, correctly predicting binding free energies of compounds to their target assist in directing the synthesis of new and promising compounds towards a particular path. Interestingly, several methods have been proposed and some are being applied to computationally predict the relative binding affinities of small molecules to their target protein. In this study, the MM-PB/GBSA and the QM/MM were used to estimate the $\mathrm{BFE}$ which takes into account changes in the gas-phase energy, solvation free energy and configurational entropy upon complex formation. The predicted BFE is estimated from the contributions obtained from the delta $\mathrm{G}_{\text {gas }}$ and deltaG $\mathrm{G}_{\text {sol }}$ (with additionally the estimated Self-Consistent-Field Energy (ESCF) for QM/MM) components as shown in Equations (5) and (6) for MM-PB/GBSA and QM/MM, respectively [102-108].

$$
\begin{gathered}
\Delta \mathrm{G}=\text { deltaG }_{\text {gas }}+\text { deltaG }_{\text {sol }} \\
\Delta \mathrm{G}=\text { deltaG }_{\text {gas }}+\text { deltaG }_{\text {sol }}+\text { ESCF }
\end{gathered}
$$

The energy contributions are further broken into different terms/components; van der Waals energy (VDWAALS) and Electrostatic energy (EEL) for $\mathrm{G}_{\text {gas }}$ phase and polar solvation energy (EGB) and Non-polar solvation energy (ESURF) for GB calculations to obtain $\mathrm{G}_{\text {sol }}$ (or polar solvation energy (EPB) and Non-polar solvation energy (ENPOLAR) for PB). Thus, Equations (5) and (6) can then be expanded to Equations (7) and (8), respectively.

$$
\begin{gathered}
\Delta \mathrm{G}=\text { VDWAALS }+ \text { EEL }+ \text { EGB }(\text { EPB })+\text { ESURF }(\text { ENPOLAR }) \\
\Delta \mathrm{G}=\text { VDWAALS }+ \text { EEL }+ \text { EGB }(\text { EPB })+\text { ESURF }(\text { ENPOLAR })+\text { ESCF }
\end{gathered}
$$

\subsection{Quantitative Structure-Activity Relationship (QSAR) Model Development and Selection}

For the development of the models, a training set of 34 molecules whose selection is described above (see Sections 3.1.1 and 3.2.1) was used. Correlating the biological activities with the estimated BFE and calculated theoretical descriptors of the ligands, QSAR-models were generated and studied using the Partial Least Square (PLS) method implemented in MOE. It is important to note that the quality of QSAR models depends on the selection 
of molecules in the dataset, distribution of the property being evaluated (in this case biological activity) and the chosen descriptors. In general parlance, models in the form of equations that provide a relationship between the dependent variable (usually biological activity) and independent variable (computed descriptors) are constructed using regression methods. In the current study, QSAR models were developed using either the different terms summing-up to the overall BFE or the total computed BFE (see Section 3.3.2. above). Several validation methods were used to validate the models developed using the training set. Models were selected based on the quality of their regression coefficient $\left(r^{2}\right)$, root mean squared error (rmse), leave-one-out cross-validated explained variance $\left(\mathrm{q}^{2}\right)$ and crossed-root mean squared error (qmse). Acceptable models were based on high $\mathrm{r}^{2}(>0.5)$ and $\mathrm{q}^{2}(>0.5)$ values with low rmse $(\leq 0.3)$ and qmse $(\leq 0.3)$ values. In general, models derived using QM/MM methods were not selected due to low $\mathrm{r}^{2}$ and $\mathrm{q}^{2}$ values. Further robust verification and internal validation of the selected models from the MM-PB/GBSA calculations were done using leave-three-molecules-out (Leave-3out) as well as a 3fold cross-validation $[109,110]$. Final models employed in this study were models that could maintain a low qmse $(<0.3)$ and $\mathrm{q}^{2}(>0.5)$ values upon the robust validations. The final models were then prospectively validated through the design, synthesis and biological validation of novel set of molecules (referred to as "test set" in this paper).

\subsection{Test Set Prediction}

To explore the reliability of the selected QSAR models, we further evaluated the predictive power of the models on an external set of molecules, which were synthesized and evaluated for their inhibitory activity on $s m$ HDAC8. The predictive power of the developed models was evaluated using the experimentally determined $\mathrm{IC}_{50}$ values which were converted to $\mathrm{pIC}_{50}$ (x-variable) and the computed BFE (y-variable). It is worth noting that the predictions were all done using the MOE software [68].

\section{Conclusions}

Although several efforts have been put in place to eradicate schistosomiasis (bilharzia); the disease continues to ravage hundreds of millions of humans in underprivileged communities. Reports on drug resistance against praziquantel (the current drug of choice) stands as a factor forcing researchers to design and develop novel anti-schistosomial compounds, especially those capable of interfering with the parasite's epigenome. In our previous publications [52-54], we showed that smHDAC8 inhibitors could be used to target the pathogen. In the current study, we explored different methods to develop several QSAR models to explain the variation of the observed biological activity using 34 previously reported $s m$ HDAC 8 inhibitors from our research group as our training set [54]. Initially, we performed docking studies to test the ability of the utilized docking settings to reproduce the binding pose of the already crystallized molecules and suggest the most probable binding pose for molecules with no crystal structures based on confirmed interactions for this chemical scaffold. However, the inability of the Glide-SP docking score to explain the variation of the reported experimental activity of the molecules prompted us to use post-processing methods (BFE calculations) to re-score the docking pose. Further attempts using predicted BFEs from different $\mathrm{GB}$ models, namely $\mathrm{GB}^{\mathrm{HCT}}(\mathrm{igb}=1), \mathrm{GB}^{\mathrm{OBC}}$ (igb = 2), $\mathrm{GB}^{\mathrm{OBC} 2}$ (igb = 5), and GBn (igb = 8), as well as PB_mbondi (mbondi), PB_bondi (bondi), PB_Parse (PARSE) using our docked poses led to the development of several QSAR models. The QSAR model (model 94) consisting of the computed BFE at the MD step using 10 frames (every fifth frame from the first frame for frames 51-100) of the PB_bondi radii calculation was selected for investigation. Further improvement of this model using a 2D descriptor and/or the removal of outliers led to models 95-97 (with correlation coefficients of $0.61,0.62$ and 0.73 , respectively) that were better in ranking and explaining the variation of the observed biological activity in the training set. Moreover, the predictive strength of models 95-97 were further validated on a set of newly designed and synthesized molecules which occupy a similar chemical space as the molecules in the training set. The predicted 
biological activities of the newly designed molecules using the models were in good accordance with the experimentally determined activity of the molecules, proving that our models possess reliable predictive power. Therefore, the models completely fulfill the requirements for the suggestion of new $5 m \mathrm{HDAC} 8$ inhibitors. We intend to use the information with regard to the binding energy of proposed $s m$ HDAC 8 inhibitors to continue the chemical optimization in order to identify new $s m$ HDAC8 inhibitors.

The prediction of HDAC selectivity based on calculated interaction energy is still challenging and was not addressed in the current manuscript. It requires high quality data, also for selectivity, obtained for a large series of compounds. Often selectivity is only measured between individual isoforms and only for a few highly promising compounds, as we did in the current study of $s m \mathrm{HDAC} 8$ inhibitors. We observed good selectivity of the compounds for $\mathrm{smHDAC} 8$ in comparison to human HDAC1 and 6, but since the activity of most of the inhibitors is rather low on these enzymes we did not determine an $\mathrm{IC}_{50}$ value for hsHDAC1/6 (only for a few compounds). Therefore, the data set included here is not suitable to do a quantitative modelling of HDAC selectivity. In case of the selectivity between human and $\operatorname{smHDAC} 8$ we obtained only low to moderate selectivity so far, which means the range of selectivity is not high enough for quantitative modelling. Therefore, novel more selective $s m / h s$ HDAC 8 inhibitors have to be developed that might be used to develop predictive BFE/QSAR models for $s m / h s H D A C 8$ selectivity.

Supplementary Materials: Table S1: Summary of re-docking and crossed-docking rmsd between the atomic coordinates of the co-crystalized ligands pose and the docked pose based on the different smHDAC8 crystalized proteins used in this study. Table S2: Summary of generated moldels. (Terms are described after the table). Table S3: summary of prediction results based on Models 95 and 96.

Author Contributions: C.V.S. carried out the docking and binding free energy calculations and wrote the paper. E.G., M.S. and S.D. synthesized compounds and provided them for in vitro testing. P.Z. carried out the in vitro testing. C.R. provided enzymes for in vitro testing. D.R. designed and supervised the docking experiments. W.S. designed and supervised the syntheses and the testing experiments and was in charge of revising and reviewing the manuscript. All authors have read and agreed to the published version of the manuscript.

Funding: This research was funded by the European Regional Development Fund of the European Commission. CR is supported by institutional funds from the Centre National de la Recherche Scientifique (CNRS), the Institut National de la Santé et de la Recherche Médicale (Inserm) and the Université de Strasbourg.

Institutional Review Board Statement: Not applicable.

Informed Consent Statement: Not applicable.

Data Availability Statement: Not applicable.

Conflicts of Interest: The authors declare no conflict of interest.

Sample Availability: Not applicable.

\section{References}

1. McManus, D.P.; Dunne, D.W.; Sacko, M.; Utzinger, J.; Vennervald, B.J.; Zhou, X.N. 1236 Schistosomiasis. Nat. Rev. Dis. Primers 2018, 4, 13. [CrossRef] [PubMed]

2. Barsoum, R.S.; Esmat, G.; El-Baz, T. Human schistosomiasis: Clinical perspective. J. Adv. Res. 2013, 4, 433-444. [CrossRef]

3. World Health Organization. Schistosomiasis Facts Sheet. 2018. Available online: https://www.who.int/news-room/fact-sheets/ detail/schistosomiasis (accessed on 18 November 2020).

4. King, C.H.; Sutherland, L.J.; Bertsch, D. Systematic review and meta-analysis of the impact of chemical-based mollusciciding for control of Schistosoma mansoni and S. haematobium transmission. PLoS Negl. Trop. Dis. 2015, 9, e0004290. [CrossRef]

5. van der Werf, M.J.; Bosompem, K.M.; de Vlas, S.J. Schistosomiasis control in Ghana: Case management and means for diagnosis and treatment within the health system. Trans. R. Soc. Trop. Med. Hyg. 2003, 97, 146-152. [CrossRef]

6. Gray, D.J.; Ross, A.G.; Li, Y.S.; McManus, D.P. Diagnosis and management of schistosomiasis. BMJ 2011, 342, d2651. [CrossRef] [PubMed] 
7. Olveda, D.U.; Olveda, R.M.; Lam, A.K.; Chau, T.N.; Li, Y.; Gisparil, A.D. Utility of diagnostic imaging in the diagnosis and management of schistosomiasis. Clin. Microbiol. 2014, 3, 142. [CrossRef]

8. Ricciardi, A.; Ndao, M. Diagnosis of parasitic infections: What's going on? J. Biomol. Screen. 2015, 20, 6-21. [CrossRef] [PubMed]

9. Da Paixão Siqueira, L.; Fontes, D.A.F.; Aguilera, C.S.B.; Timóteo, T.R.R.; Ângelos, M.A.; Silva, L.C.P.B.B.; de Melo, C.G.; Rolim, L.A.; da Silva, R.M.F.; Neto, P.J.R. Schistosomiasis: Drugs used and treatment strategies. Acta Trop. 2017, 176, 179-187. [CrossRef] [PubMed]

10. Cioli, D.; Pica-Mattoccia, L.; Basso, A.; Guidi, A. Schistosomiasis control: Praziquantel forever? Mol. Biochem. Parasitol. 2014, 195, 23-29. [CrossRef] [PubMed]

11. Hailu, G.S.; Robaa, D.; Forgione, M.; Sippl, W.; Rotili, D.; Mai, A. Lysine deacetylase inhibitors in parasites: Past, present, and future perspectives. J. Med. Chem. 2017, 60, 4780-4804. [CrossRef]

12. Jeffers, V.; Yang, C.; Huang, S.; Sullivan, W.J. Bromodomains in protozoan parasites: Evolution, function, and opportunities for drug development. Microbiol. Mol. Biol. Rev. 2017, 81. [CrossRef] [PubMed]

13. Zuma, A.A.; Souza, W.D. Histone deacetylases as targets for antitrypanosomal drugs. Future Sci. OA 2018, 4, FSO325. [CrossRef] [PubMed]

14. Mai, A.; Massa, S.; Rotili, D.; Cerbara, I.; Valente, S.; Pezzi, R.; Simeoni, S.; Ragno, R. Histone deacetylation in epigenetics: An attractive target for anticancer therapy. Med. Res. Rev. 2005, 25, 261-309. [CrossRef]

15. Ruijter, A.J.D.; Gennip, A.H.V.; Caron, H.N.; Kemp, S.; Kuilenburg, A.B.V. Histone deacetylases (HDACs): Characterization of the classical HDAC family. Biochem. J. 2003, 370, 737-749. [CrossRef] [PubMed]

16. Blander, G.; Guarente, L. The Sir2 family of protein deacetylases. Annu. Rev. Biochem. 2004, 73, 417-435. [CrossRef] [PubMed]

17. Buck, S.W.; Gallo, C.M.; Smith, J.S. Diversity in the Sir2 family of protein deacetylases. J. Leukoc. Biol. 2004, 75, 939-950. [CrossRef]

18. Kim, H.J.; Bae, S.C. Histone deacetylase inhibitors: Molecular mechanisms of action and clinical trials as anti-cancer drugs. Am. J. Transl. Res. 2011, 3, 166.

19. Lombardi, P.M.; Cole, K.E.; Dowling, D.P.; Christianson, D.W. Structure, mechanism, and inhibition of histone deacetylases and related metalloenzymes. Curr. Opin. Struct. Biol. 2011, 21, 735-743. [CrossRef] [PubMed]

20. Xu, W.S.; Parmigiani, R.B.; Marks, P.A. Histone deacetylase inhibitors: Molecular mechanisms of action. Oncogene 2007, 26, 5541-5552. [CrossRef] [PubMed]

21. Andrews, K.T.; Haque, A.; Jones, M.K. HDAC inhibitors in parasitic diseases. Immunol. Cell Biol. 2012, 90, 66-77. [CrossRef] [PubMed]

22. Andrews, K.T.; Tran, T.N.; Fairlie, D.P. Towards histone deacetylase inhibitors as new antimalarial drugs. Curr. Pharm. Des. 2012, 18, 3467-3479. [CrossRef]

23. Ingram, A.K.; Horn, D. Histone deacetylases in Trypanosoma brucei: Two are essential and another is required for normal cell cycle progression. Mol. Microbiol. 2002, 45, 89-97. [CrossRef] [PubMed]

24. Ouaissi, M.; Ouaissi, A. Histone deacetylase enzymes as potential drug targets in cancer and parasitic diseases. J. Biomed. Biotechnol. 2006. [CrossRef] [PubMed]

25. Pierce, R.J.; Dubois-Abdesselem, F.; Lancelot, J.; Andrade, L.; Oliveira, G. Targeting schistosome histone modifying enzymes for drug development. Curr. Pharm. Des. 2012, 18, 3567-3578. [CrossRef]

26. Ning, Z.Q.; Li, Z.B.; Newman, M.J.; Shan, S.; Wang, X.H.; Pan, D.S.; Zhang, J.; Dong, M.; Du, X.; Lu, X.P. Chidamide (CS055/HBI8000): A new histone deacetylase inhibitor of the benzamide class with antitumor activity and the ability to enhance immune cell-mediated tumor cell cytotoxicity. Cancer Chemother. Pharmacol. 2012, 69, 901-909. [CrossRef] [PubMed]

27. Atadja, P. Development of the pan-DAC inhibitor panobinostat (LBH589): Successes and challenges. Cancer Lett. 2009, 280, 233-241. [CrossRef] [PubMed]

28. Khan, N.; Jeffers, M.; Kumar, S.; Hackett, C.; Boldog, F.; Khramtsov, N.; Qian, X.; Mills, E.; Berghs, S.C.; Carey, N.; et al. Determination of the class and isoform selectivity of small-molecule histone deacetylase inhibitors. Biochem. J. 2008, 409, 581-589. [CrossRef]

29. Jones, P.; Altamura, S.; De Francesco, R.; Paz, O.G.; Kinzel, O.; Mesiti, G.; Monteagudo, E.; Pescatore, G.; Rowley, M.; Verdirame, M.; et al. A novel series of potent and selective ketone histone deacetylase inhibitors with antitumor activity in vivo. J. Med. Chem. 2008, 51, 2350-2353. [CrossRef]

30. Lee, J.H.; Mahendran, A.; Yao, Y.; Ngo, L.; Venta-Perez, G.; Choy, M.L.; Kim, N.; Ham, W.S.; Breslow, R.; Marks, P.A. Development of a histone deacetylase 6 inhibitor and its biological effects. Proc. Natl. Acad. Sci. USA 2013, 110, 15704-15709. [CrossRef]

31. Lee, J.H.; Yao, Y.; Mahendran, A.; Ngo, L.; Venta-Perez, G.; Choy, M.L.; Breslow, R.; Marks, P.A. Development of a histone deacetylase 6 inhibitor and its biological effects. Proc. Natl. Acad. Sci. USA 2015, 112, 12005-12010. [CrossRef]

32. Ito, T.; Ouchida, M.; Morimoto, Y.; Yoshida, A.; Jitsumori, Y.; Ozaki, T.; Sonobe, H.; Inoue, H.; Shimizu, K. Significant growth suppression of synovial sarcomas by the histone deacetylase inhibitor FK228 in vitro and in vivo. Cancer Lett. 2005, 224, 311-319. [CrossRef] [PubMed]

33. Daniel, K.B.; Sullivan, E.D.; Chen, Y.; Chan, J.C.; Jennings, P.A.; Fierke, C.A.; Cohen, S.M. Dual-mode HDAC prodrug for covalent modification and subsequent inhibitor release. J. Med. Chem. 2015, 58, 4812-4821. [CrossRef] [PubMed]

34. Furumai, R.; Komatsu, Y.; Nishino, N.; Khochbin, S.; Yoshida, M.; Horinouchi, S. Potent histone deacetylase inhibitors built from trichostatin A and cyclic tetrapeptide antibiotics including trapoxin. Proc. Natl. Acad. Sci. USA 2001, 98, 87-92. [CrossRef] 
35. Kijima, M.; Yoshida, M.; Sugita, K.; Horinouchi, S.; Beppu, T. Trapoxin, an antitumor cyclic tetrapeptide, is an irreversible inhibitor of mammalian histone deacetylase. J. Biol. Chem. 1993, 268, 22429-22435. [CrossRef]

36. Day, J.A.; Cohen, S.M. Investigating the selectivity of metalloenzyme inhibitors. J. Med. Chem. 2013, 56, 7997-8007. [CrossRef]

37. Bradner, J.E.; West, N.; Grachan, M.L.; Greenberg, E.F.; Haggarty, S.J.; Warnow, T.; Mazitschek, R. Chemical phylogenetics of histone deacetylases. Nat. Chem. Biol. 2010, 6, 238-243. [CrossRef]

38. Chen, A.Y.; Adamek, R.N.; Dick, B.L.; Credille, C.V.; Morrison, C.N.; Cohen, S.M. Targeting metalloenzymes for therapeutic intervention. Chem. Rev. 2018, 119, 1323-1455. [CrossRef] [PubMed]

39. Jung, M.; Brosch, G.; Kölle, D.; Scherf, H.; Gerhäuser, C.; Loidl, P. Amide analogues of trichostatin A as inhibitors of histone deacetylase and inducers of terminal cell differentiation. J. Med. Chem. 1999, 42, 4669-4679. [CrossRef]

40. Wang, X.X.; Wan, R.Z.; Liu, Z.P. Recent advances in the discovery of potent and selective HDAC6 inhibitors. Eur. J. Med. Chem. 2018, 143, 1406-1418. [CrossRef]

41. Moradei, O.; Maroun, C.R.; Paquin, I.; Vaisburg, A. Histone deacetylase inhibitors: Latest developments, trends and prospects. Curr. Med. Chem. Anti Cancer Agents 2005, 5, 529-560. [CrossRef]

42. Paris, M.; Porcelloni, M.; Binaschi, M.; Fattori, D. Histone deacetylase inhibitors: From bench to clinic. J. Med. Chem. 2008, 51, 1505-1529. [CrossRef] [PubMed]

43. Lauffer, B.E.; Mintzer, R.; Fong, R.; Mukund, S.; Tam, C.; Zilberleyb, I.; Flicke, B.; Ritscher, A.; Fedorowicz, G.; Vallero, R.; et al. Histone deacetylase (HDAC) inhibitor kinetic rate constants correlate with cellular histone acetylation but not transcription and cell viability. J. Biol. Chem. 2013, 288, 26926-26943. [CrossRef] [PubMed]

44. Lobera, M.; Madauss, K.P.; Pohlhaus, D.T.; Wright, Q.G.; Trocha, M.; Schmidt, D.R.; Baloglu, E.; Trump, R.P.; Head, M.S.; Hofmann, G.A.; et al. Selective class IIa histone deacetylase inhibition via a nonchelating zinc-binding group. Nat. Chem. Biol. 2013, 9, 319-325. [CrossRef] [PubMed]

45. Porter, N.J.; Mahendran, A.; Breslow, R.; Christianson, D.W. Unusual zinc-binding mode of HDAC6-selective hydroxamate inhibitors. Proc. Natl. Acad. Sci. USA 2017, 114, 13459-13464. [CrossRef] [PubMed]

46. Micelli, C.; Rastelli, G. Histone deacetylases: Structural determinants of inhibitor selectivity. Drug Discov. Today 2015, 20, 718-735. [CrossRef]

47. Miyake, Y.; Keusch, J.J.; Wang, L.; Saito, M.; Hess, D.; Wang, X.; Melancon, B.J.; Helquist, P.; Gut, H.; Matthias, P. Structural insights into HDAC6 tubulin deacetylation and its selective inhibition. Nat. Chem. Biol. 2016, 12, 748-754. [CrossRef]

48. Hai, Y.; Christianson, D.W. Histone deacetylase 6 structure and molecular basis of catalysis and inhibition. Nat. Chem. Biol. 2016, 12, 741-747. [CrossRef]

49. Marek, M.; Kannan, S.; Hauser, A.T.; Mourao, M.M.; Caby, S.; Cura, V.; Stolfa, D.A.; Schmidtkunz, K.; Lancelot, J.; Andrade, L.; et al. Structural basis for the inhibition of histone deacetylase 8 (HDAC8), a key epigenetic player in the blood fluke Schistosoma mansoni. PLoS Pathog. 2013, 9, e1003645. [CrossRef]

50. Melesina, J.; Praetorius, L.; Simoben, C.V.; Robaa, D.; Sippl, W. Design of selective histone deacetylase inhibitors: Rethinking classical pharmacophore. Future Med. Chem. 2018, 10, 1537-1540. [CrossRef]

51. Nakagawa, M.; Oda, Y.; Eguchi, T.; Aishima, S.I.; Yao, T.; Hosoi, F.; Basaki, Y.; Ono, M.; Kuwano, M.; Tanaka, M.; et al. Expression profile of class I histone deacetylases in human cancer tissues. Oncol. Rep. 2007, 18, 769-774. [CrossRef]

52. Simoben, C.V.; Robaa, D.; Chakrabarti, A.; Schmidtkunz, K.; Marek, M.; Lancelot, J.; Kannan, S.; Melesina, J.; Shaik, T.B.; Pierce, R.J.; et al. A novel class of Schistosoma mansoni histone deacetylase 8 (HDAC8) inhibitors identified by structure-based virtual screening and in vitro testing. Molecules 2018, 23, 566. [CrossRef]

53. Kannan, S.; Melesina, J.; Hauser, A.T.; Chakrabarti, A.; Heimburg, T.; Schmidtkunz, K.; Walter, A.; Marek, M.; Pierce, R.J.; Romier, C.; et al. Discovery of inhibitors of Schistosoma mansoni HDAC8 by combining homology modeling, virtual screening, and in vitro validation. J. Chem. Inf. Model. 2014, 54, 3005-3019. [CrossRef]

54. Heimburg, T.; Chakrabarti, A.; Lancelot, J.; Marek, M.; Melesina, J.; Hauser, A.T.; Shaik, T.B.; Duclaud, S.; Robaa, D.; Erdmann, F.; et al. Structure-based design and synthesis of novel inhibitors targeting HDAC8 from Schistosoma mansoni for the treatment of schistosomiasis. J. Med. Chem. 2016, 59, 2423-2435. [CrossRef]

55. Feig, M.; Onufriev, A.; Lee, M.S.; Im, W.; Case, D.A.; Brooks, C.L., III. Performance comparison of generalized born and Poisson methods in the calculation of electrostatic solvation energies for protein structures. J. Comput. Chem. 2004, 25, 265-284. [CrossRef]

56. Hawkins, G.D.; Cramer, C.J.; Truhlar, D.G. Parametrized models of aqueous free energies of solvation based on pairwise descreening of solute atomic charges from a dielectric medium. J. Phys. Chem. 1996, 100, 19824-19839. [CrossRef]

57. Mongan, J.; Simmerling, C.; McCammon, J.A.; Case, D.A.; Onufriev, A. Generalized Born model with a simple, robust molecular volume correction. J. Chem. Theory Comput. 2007, 3, 156-169. [CrossRef] [PubMed]

58. Onufriev, A.; Bashford, D.; Case, D.A. Modification of the generalized Born model suitable for macromolecules. J. Phys. Chem. B 2000, 104, 3712-3720. [CrossRef]

59. Onufriev, A.; Bashford, D.; Case, D.A. Exploring protein native states and large-scale conformational changes with a modified generalized born model. Proteins: Struct. Funct. Bioinform. 2004, 55, 383-394. [CrossRef] [PubMed]

60. Onufriev, A.; Case, D.A.; Bashford, D. Effective Born radii in the generalized Born approximation: The importance of being perfect. J. Comput. Chem. 2002, 23, 1297-1304. [CrossRef] [PubMed]

61. Dewar, M.J.; Zoebisch, E.G.; Healy, E.F.; Stewart, J.J. Development and use of quantum mechanical molecular models. 76. AM1: A new general purpose quantum mechanical molecular model. J. Am. Chem. Soc. 1985, 107, 3902-3909. [CrossRef] 
62. Dewar, M.J.; Zoebisch, E.G.; Healy, E.F.; Stewart, J.J. Development and use of quantum mechanical molecular models. 76. AM1: A new general purpose quantum mechanical molecular model. [Erratum to document cited in CA103 (2): 11627f]. J. Am. Chem. Soc. 1993, 115, 5348. [CrossRef]

63. Stewart, J.J. Semiempirical molecular orbital methods. Rev. Comput. Chem. 1990, 1, 45-81.

64. Stewart, J.J. Optimization of parameters for semiempirical methods II. Applications. J. Comput. Chem. 1989, 10, 221-264. [CrossRef]

65. Stewart, J.J. Optimization of parameters for semiempirical methods. III Extension of PM3 to Be, Mg, Zn, Ga, Ge, As, Se, Cd, In, $\mathrm{Sn}, \mathrm{Sb}, \mathrm{Te}, \mathrm{Hg}, \mathrm{Tl}, \mathrm{Pb}$, and Bi. J. Comput. Chem. 1991, 12, 320-341.

66. Stewart, J.J. Optimization of parameters for semiempirical methods IV: Extension of MNDO, AM1, and PM3 to more main group elements. J. Mol. Model. 2004, 10, 155-164. [CrossRef] [PubMed]

67. Stolfa, D.A.; Marek, M.; Lancelot, J.; Hauser, A.T.; Walter, A.; Leproult, E.; Melesina, J.; Rumpf, T.; Wurtz, J.M.; Cavarelli, J.; et al. Molecular basis for the antiparasitic activity of a mercaptoacetamide derivative that inhibits histone deacetylase 8 (HDAC8) from the human pathogen Schistosoma mansoni. J. Mol. Biol. 2014, 426, 3442-3453. [CrossRef]

68. Molecular Operating Environment (MOE) MOE. 2013.08; Chemical Computing Group ULC, 1010 Sherbooke St. West, Suite \#910, Montreal, QC, Canada, H3A 2R7. 2019. Available online: https://www.chemcomp.com/Products.htm (accessed on 2 August 2019).

69. Jolliffe, I.T.; Cadima, J. Principal component analysis: A review and recent developments. Philos. Trans. R. Soc. A Math. Phys. Eng. Sci. 2016, 374, 20150202. [CrossRef]

70. Carey, R.N.; Wold, S.; Westgard, J.O. Principal component analysis. Alternative to referee methods in method comparison studies. Anal. Chem. 1975, 47, 1824-1829. [CrossRef]

71. Marek, M.; Shaik, T.B.; Heimburg, T.; Chakrabarti, A.; Lancelot, J.; Ramos-Morales, E.; Da Veiga, C.; Kalinin, D.; Melesina, J.; Robaa, D.; et al. Characterization of histone deacetylase 8 (HDAC8) selective inhibition reveals specific active site structural and functional determinants. J. Med. Chem. 2018, 61, 10000-10016. [CrossRef]

72. Schrödinger. LigPrep; Release Version 2017-2; Schrödinger, LLC: New York, NY, USA, 2017.

73. Banks, J.L.; Beard, H.S.; Cao, Y.; Cho, A.E.; Damm, W.; Farid, R.; Felts, A.K.; Halgren, T.A.; Mainz, D.T.; Maple, J.R.; et al. Integrated modeling program, applied chemical theory (IMPACT). J. Comput. Chem. 2005, 26, 1752-1780. [CrossRef]

74. Release, S. ConfGen; 2017-2; Schrödinger, LLC: New York, NY, USA, 2017.

75. Watts, K.S.; Dalal, P.; Murphy, R.B.; Sherman, W.; Friesner, R.A.; Shelley, J.C. ConfGen: A conformational search method for efficient generation of bioactive conformers. J. Chem. Inf. Model. 2010, 50, 534-546. [CrossRef]

76. Burley, S.K.; Berman, H.M.; Christie, C.; Duarte, J.M.; Feng, Z.; Westbrook, J.; Young, J.; Zardecki, C. RCSB Protein Data Bank: Sustaining a living digital data resource that enables breakthroughs in scientific research and biomedical education. Protein Sci. 2018, 27, 316-330. [CrossRef] [PubMed]

77. Schrödinger. Schrödinger Suite 2017-1 Protein Preparation Wizard; Release 2017-1; Schrödinger, LLC: New York, NY, USA, 2017.

78. Sastry, G.M.; Adzhigirey, M.; Day, T.; Annabhimoju, R.; Sherman, W. Protein and ligand preparation: Parameters, protocols, and influence on virtual screening enrichments. J. Comput. Aided Mol. Des. 2013, 27, 221-234. [CrossRef] [PubMed]

79. Schrödinger. Release 2017-2: Epik; Schrödinger, LLC: New York, NY, USA, 2017.

80. Shelley, J.C.; Cholleti, A.; Frye, L.L.; Greenwood, J.R.; Timlin, M.R.; Uchimaya, M. Epik: A software program for pK a prediction and protonation state generation for drug-like molecules. J. Comput. Aided Mol. Des. 2007, 21, 681-691. [CrossRef]

81. Friesner, R.A.; Banks, J.L.; Murphy, R.B.; Halgren, T.A.; Klicic, J.J.; Mainz, D.T.; Repasky, M.P.; Knoll, E.H.; Shelley, M.; Perry, J.K.; et al. Glide: A new approach for rapid, accurate docking and scoring. 1. Method and assessment of docking accuracy. J. Med. Chem. 2004, 47, 1739-1749. [CrossRef] [PubMed]

82. Halgren, T.A.; Murphy, R.B.; Friesner, R.A.; Beard, H.S.; Frye, L.L.; Pollard, W.T.; Banks, J.L. Glide: A new approach for rapid, accurate docking and scoring. 2. Enrichment factors in database screening. J. Med. Chem. 2004, 47, 1750-1759. [CrossRef] [PubMed]

83. Schrödinger. Glide; Release 2017-2; Schrödinger, LLC: New York, NY, USA, 2017.

84. David, L.; Luo, R.; Gilson, M.K. Comparison of generalized Born and Poisson models: Energetics and dynamics of HIV protease. J. Comput. Chem. 2000, 21, 295-309. [CrossRef]

85. Jorgensen, W.L.; Chandrasekhar, J.; Madura, J.D.; Impey, R.W.; Klein, M.L. Comparison of simple potential functions for simulating liquid water. J. Chem. Phys. 1983, 79, 926-935. [CrossRef]

86. Liu, H.Y.; Zou, X. Electrostatics of ligand binding: Parametrization of the generalized born model and comparison with the Poisson- Boltzmann approach. J. Phys. Chem. B 2006, 110, 9304-9313. [CrossRef] [PubMed]

87. Li, P.; Roberts, B.P.; Chakravorty, D.K.; Merz, K.M., Jr. Rational design of particle mesh Ewald compatible Lennard-Jones parameters for+ 2 metal cations in explicit solvent. J. Chem. Theory Comput. 2013, 9, 2733-2748. [CrossRef]

88. Li, P.; Song, L.F.; Merz, K.M., Jr. Systematic parameterization of monovalent ions employing the nonbonded model. J. Chem. Theory Comput. 2015, 11, 1645-1657. [CrossRef]

89. Najjar, A.; Platzer, C.; Luft, A.; Aßmann, C.A.; Elghazawy, N.H.; Erdmann, F.; Sippl, W.; Schmidt, M. Computer-aided design, synthesis and biological characterization of novel inhibitors for PKMYT1. Eur. J. Med. Chem. 2019, 161, 479-492. [CrossRef]

90. Case, D.A.; Betz, R.M.; Cerutti, D.S.; Cheatham, T.E., III; Darden, T.A.; Duke, R.E.; Giese, T.J.; Gohlke, H.; Goetz, A.W.; Homeyer, N.; et al. AMBER 2016; University of California: San Francisco, CA, USA, 2016. 
91. Duan, Y.; Wu, C.; Chowdhury, S.; Lee, M.C.; Xiong, G.; Zhang, W.; Yang, R.; Cieplak, P.; Luo, R.; Lee, T.; et al. A point-charge force field for molecular mechanics simulations of proteins based on condensed-phase quantum mechanical calculations. J. Comput. Chem. 2003, 24, 1999-2012. [CrossRef]

92. Lee, M.C.; Duan, Y. Distinguish protein decoys by using a scoring function based on a new AMBER force field, short molecular dynamics simulations, and the generalized born solvent model. Proteins: Struct. Funct. Bioinform. 2004, 55, 620-634. [CrossRef] [PubMed]

93. Wang, J.; Wolf, R.M.; Caldwell, J.W.; Kollman, P.A.; Case, D.A. Development and testing of a general amber force field. J. Comput. Chem. 2004, 25, 1157-1174. [CrossRef]

94. Li, P.; Song, L.F.; Merz, K.M., Jr. Parameterization of highly charged metal ions using the 12-6-4 LJ-type nonbonded model in explicit water. J. Phys. Chem. B 2015, 119, 883-895. [CrossRef]

95. Lee, T.S.; Hu, Y.; Sherborne, B.; Guo, Z.; York, D.M. Toward fast and accurate binding affinity prediction with pmemdGTI: An efficient implementation of GPU-accelerated thermodynamic integration. J. Chem. Theory Comput. 2017, 13, 3077-3084. [CrossRef] [PubMed]

96. Le Grand, S.; Götz, A.W.; Walker, R.C. SPFP: Speed without compromise-A mixed precision model for GPU accelerated molecular dynamics simulations. Comput. Phys. Commun. 2013, 184, 374-380. [CrossRef]

97. Sagui, C.; Pedersen, L.G.; Darden, T.A. Towards an accurate representation of electrostatics in classical force fields: Efficient implementation of multipolar interactions in biomolecular simulations. J. Chem. Phys. 2004, 120, 73-87. [CrossRef]

98. Toukmaji, A.; Sagui, C.; Board, J.; Darden, T. Efficient particle-mesh Ewald based approach to fixed and induced dipolar interactions. J. Chem. Phys. 2000, 113, 10913-10927. [CrossRef]

99. Miller, B.R., III; McGee, T.D., Jr.; Swails, J.M.; Homeyer, N.; Gohlke, H.; Roitberg, A.E. MMPBSA.py: An efficient program for end-state free energy calculations. J. Chem. Theory Comput. 2012, 8, 3314-3321. [CrossRef] [PubMed]

100. Wollacott, A.M.; Merz, K.M. Development of a parametrized force field to reproduce semiempirical geometries. J. Chem. Theory Comput. 2006, 2, 1070-1077. [CrossRef] [PubMed]

101. Voityuk, A.A.; Bliznyuk, A.A.; Burshtein, K.Y. Revised semiempirical parameters for Br, I, Sn, $\mathrm{Hg}$, and $\mathrm{Pb}$ in the MNDO method. J. Struct. Chem. 1987, 28, 9-12. [CrossRef]

102. Åqvist, J.; Medina, C.; Samuelsson, J.E. A new method for predicting binding affinity in computer-aided drug design. Protein Eng. Des. Sel. 1994, 7, 385-391. [CrossRef]

103. Holst, M.; Saied, F. Multigrid solution of the Poisson-Boltzmann equation. J. Comput. Chem. 1993, 14, 105-113. [CrossRef]

104. Holst, M.J.; Saied, F. Numerical solution of the nonlinear Poisson-Boltzmann equation: Developing more robust and efficient methods. J. Comput. Chem. 1995, 16, 337-364. [CrossRef]

105. Homeyer, N.; Gohlke, H. Free energy calculations by the molecular mechanics Poisson—Boltzmann surface area method. Mol. Inform. 2012, 31, 114-122. [CrossRef]

106. Homeyer, N.; Gohlke, H. FEW: A workflow tool for free energy calculations of ligand binding. J. Comput. Chem. 2013, 34, 965-973. [CrossRef]

107. Kollman, P.A.; Massova, I.; Reyes, C.; Kuhn, B.; Huo, S.; Chong, L.; Lee, M.; Lee, T.; Duan, Y.; Wang, W.; et al. Calculating structures and free energies of complex molecules: Combining molecular mechanics and continuum models. Acc. Chem. Res. 2000, 33, 889-897. [CrossRef]

108. Lee, M.R.; Duan, Y.; Kollman, P.A. Use of MM-PB/SA in estimating the free energies of proteins: Application to native, intermediates, and unfolded villin headpiece. Proteins Struct. Funct. Bioinform. 2000, 39, 309-316. [CrossRef]

109. Thalheim, T. cvq2-Package: Calculate the Predictive Squared Correlation Coefficient. 2013. Available online: https://CRAN.Rproject.org/package $=\mathrm{cvq} 2$ (accessed on 14 February 2020).

110. RStudio Team. RStudio: Integrated Development for R; RStudio, Inc.: Boston, MA, USA, 2015. Available online: http://www. rstudio.com/ (accessed on 1 February 2020). 